\section{Ultrasonography of the scrotum in adults}

\author{
Anna L. Kühn, Eduardo Scortegagna, Kristina M. Nowitzki, Young H. Kim \\ Department of Radiology, UMass Memorial Medical Center, University of Massachusetts \\ Medical Center, Worcester, MA, USA
}

Ultrasonography is the ideal noninvasive imaging modality for evaluation of scrotal abnormalities. It is capable of differentiating the most important etiologies of acute scrotal pain and swelling, including epididymitis and testicular torsion, and is the imaging modality of choice in acute scrotal trauma. In patients presenting with palpable abnormality or scrotal swelling, ultrasonography can detect, locate, and characterize both intratesticular and extratesticular masses and other abnormalities. A 12-17 MHz high frequency linear array transducer provides excellent anatomic detail of the testicles and surrounding structures. In addition, vascular perfusion can be easily assessed using color and spectral Doppler analysis. In most cases of scrotal disease, the combination of clinical history, physical examination, and information obtained with ultrasonography is sufficient for diagnostic decision-making. This review covers the normal scrotal anatomy as well as various testicular and scrotal lesions.

Keywords: Testicle; Scrotum; Spermatic cord torsion; Orchitis; Ultrasonography

\section{Introduction}

Ultrasonography is an essential imaging modality in diagnosing testicular and scrotal pathology, as it provides fine anatomical details of the testicle and surrounding structures and evaluates vascular perfusion in real time. Clinical examination often yields nonspecific signs and symptoms such as scrotal pain, swelling or a palpable scrotal mass. Ultrasonography is able to identify and characterize intratesticular or extratesticular lesions and is often able to distinguish between benign or malignant lesions as well as identify conditions that require emergent surgical intervention. In addition, ultrasonography is a safe, relatively inexpensive, and readily available imaging modality that does not require ionizing radiation. This pictorial review provides an overview of the ultrasonographic anatomy of the scrotum followed by diagnosis of a variety of intra- and extratesticular lesions based on different clinical manifestations.

\section{Normal Scrotal Anatomy on Ultrasonography}

Both testicles lie within the scrotum, a fibromuscular sac divided into the right and left hemiscrotum by a midline septum (raphe). The normal male testicle is an ovoid structure measuring approximately $5 \times 3 \times 2 \mathrm{~cm}$ (length $\times$ height $\times$ breadth) with a homogeneous, intermediate echogenicity (Fig. 1). The epididymis is a comma-shaped, elongated structure located at the posterior border of the testicle and is divided into the head, tail, and body. The epididymal head overhangs the superior pole of the testicle and is isoechoic or slightly hyperechoic to the adjacent testicular tissue. The epididymal body

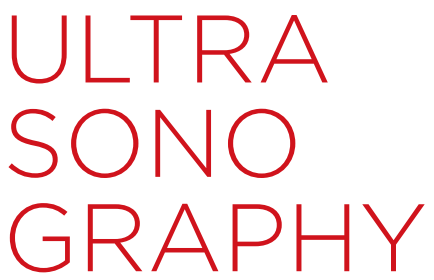

\section{REVIEW ARTICLE}

http://dx.doi.org/10.14366/usg.15075 pISSN: 2288-5919 • elSSN: 2288-5943 Ultrasonography 2016;35:180-197

Received: November 19, 2015

Revised: February 21, 2016

Accepted: February 24, 2016

Correspondence to:

Young H. Kim, MD, Department of Radiology, UMass Memorial Medical Center, University of Massachusetts Medical School, 55 Lake Avenue North, Worcester, MA 01655, USA

Tel. +1-508-334-2087

Fax. +1-508-856-1860

E-mail: Kimy@ummhc.org

This is an Open Access article distributed under the terms of the Creative Commons Attribution NonCommercial License (http://creativecommons.org/ licenses/by-nc/3.0/) which permits unrestricted noncommercial use, distribution, and reproduction in any medium, provided the original work is properly cited

Copyright @ 2016 Korean Society of Ultrasound in Medicine (KSUM)

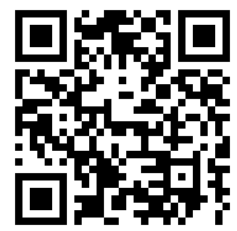

How to cite this article:

Kühn AL, Scortegagna E, Nowitzki KM, Kim $\mathrm{YH}$. Ultrasonography of the scrotum in adults. Ultrasonography. 2016 Jul;35(3):180-197. 


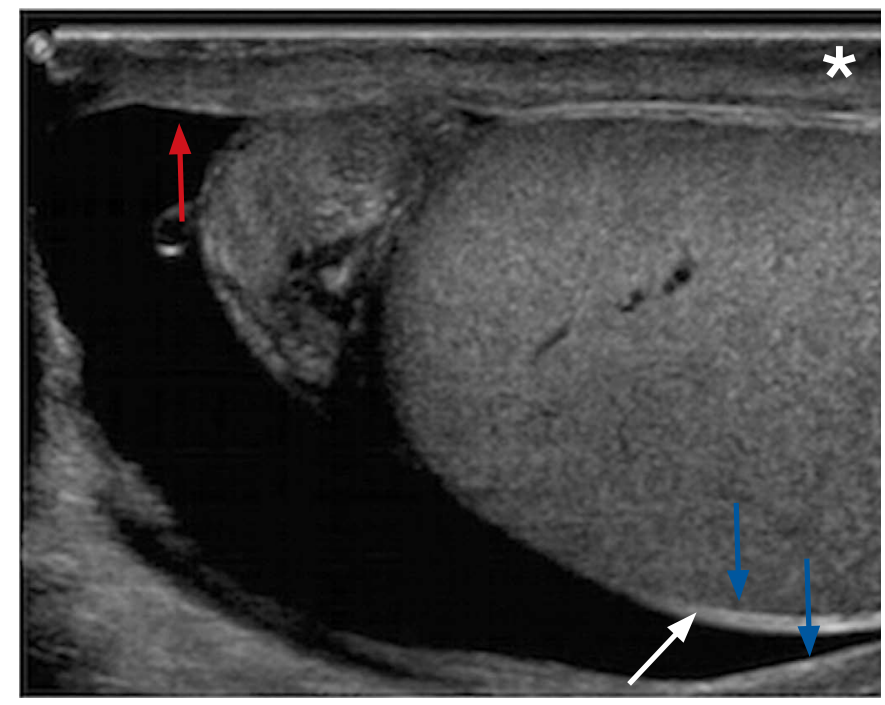

Fig. 1. Tunica albuginea and tunica vaginalis of a 22-year-old male with right scrotal pain. Sonogram of the testicle effectively demonstrates the tunica albuginea which envelopes the testicle (red arrow). The testicle with its tunica albuginea is covered by the visceral layer of the tunica vaginalis (white arrow). The inner aspect of the scrotal wall (asterisk) is covered by the parietal layer of the tunica vaginalis (blue arrows). Normally both layers of the tunica vaginalis are only separated by a small amount of fluid; however, in this case there is a moderate amount of fluid separating the two layers that allows a good demonstration of the anatomy.

and tail are located behind and along the inferior pole of the testicle and are usually isoechoic to the testis. Anatomically, they are located behind and at the inferior pole of the testicle.

Within each hemiscrotum, the testicle and epididymis are enclosed by a fibrous capsule, the tunica albuginea. On ultrasonography, the capsule is seen as a thin echogenic band outlining the testis.

The tunica albuginea is covered by the tunica vaginalis, a remnant of the processus vaginalis, which represents a closed sac of peritoneum consisting of two layers. The visceral layer lines the tunica albuginea of the testis and is separated from the parietal layer that lines the inner aspect of the scrotal wall by a small amount of fluid-containing interspace. The tunica albuginea extends into the posteromedial testis to form the mediastinum testis (Fig. 2), which contains ducts, nerves and blood vessels. The mediastinum is usually seen on ultrasonography as a thin echogenic band. There are several fibrous septa that extend from the mediastinum testis in order to divide the testicle into multiple small lobules. These lobules contain seminiferous tubules, which converge to form the tubuli recti, testicular ducts that open into the rete testis. In about $20 \%$ of patients, the rete testis can be identified as a hypoechoic area adjacent to the mediastinum testis [1].

Efferent ductules exit the rete testis and drain into the epididymal

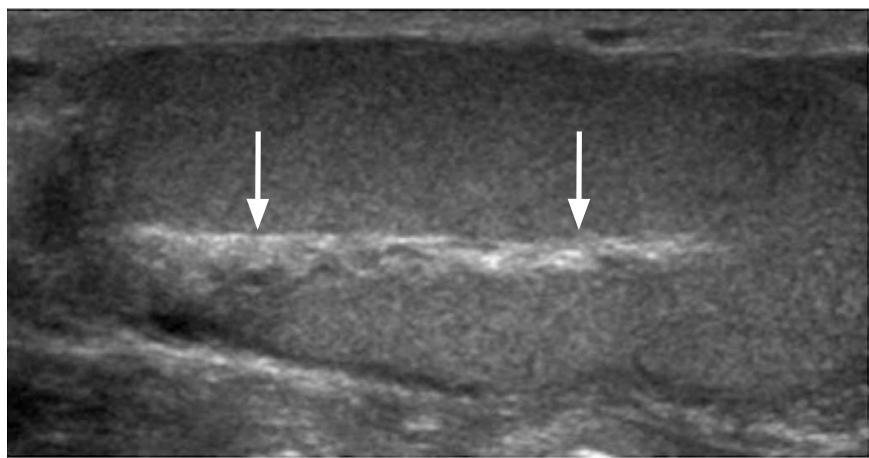

Fig. 2. Mediastinum testis of a 25-year-old male with scrotal pain. The mediastinum testis (arrows) is an echogenic band running across the posteromedial aspect of the testicle. It is contiguous with the tunica albuginea and receives the blood vessels, lymphatics, nerves, and ducts that serve the testis.

head. From the epididymal head, the ducts converge into a single duct within the epididymal body that exits the epididymal tail as the vas deferens. The vas deferens then courses superiorly within the inguinal canal as part of the spermatic cord. In addition to the vas deferens, the spermatic cord contains nerves, lymphatic ducts, arteries (testicular artery, deferential artery, and cremasteric artery) and the pampiniform venous plexus. On ultrasonography, the spermatic cord appears as a highly echogenic band within the inguinal canal.

The pampiniform venous plexus continues as the testicular vein in the deep inguinal canal. The left testicular vein drains via the left renal vein into the inferior vena cava (IVC) whereas the right testicular vein drains directly into the IVC.

Epididymal and testicular appendages represent embryologic remnants that can be identified on ultrasonography, especially when a hydrocele is present. The appendix testis (hydatid of Morgagni) is seen as an isoechoic, oval structure located between the epididymis and testis (Fig. 3). An appendix epididymis is an often-pedunculated structure arising from the epididymal head, which also appears isoechoic to testicular tissue (Fig. 4).

\section{Technique and Scanning Protocol}

Ultrasonography of the scrotum includes greyscale and color Doppler evaluation of testicles, epididymides, and the scrotum. Spectral Doppler evaluation is performed to demonstrate appropriate waveforms within the testicular artery and vein. Usually, a high frequency, broad bandwidth 17-5 MHz or 12-5 MHz transducer is used. The testicles and scrotum are elevated and supported with a towel placed underneath the scrotum. The patient holds another towel to retract and cover the penis. 


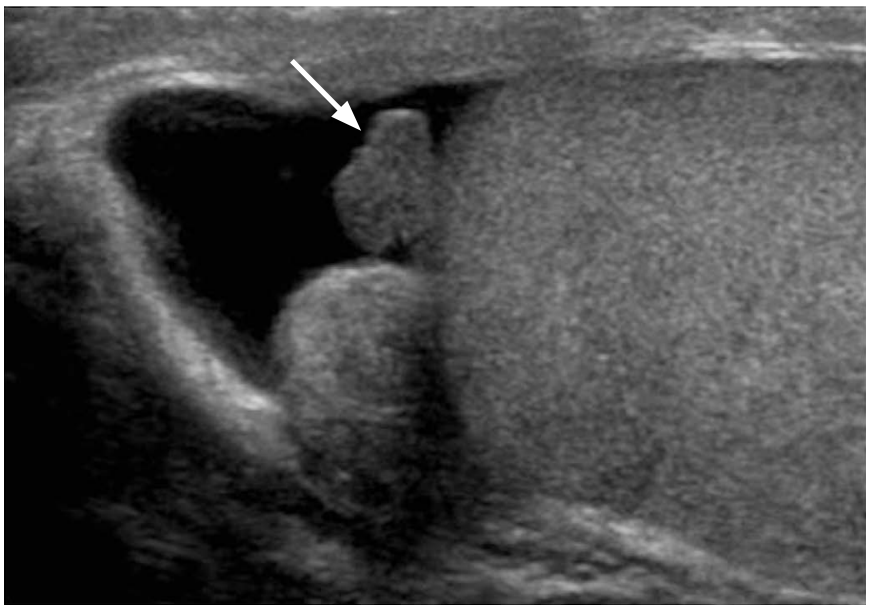

Fig. 3. Appendix testis of a 22-year-old male with scrotal pain appearing as an isoechoic, oval-shaped structure (arrow) located between the epididymal head and testicle. It represents a developmental remnant of the Müllerian (paramesonephric) duct.

Many scanning protocols begin with a side-by-side, large fieldof-view image including both testicles using both grayscale and color Doppler techniques. This allows for comparison of testicular echogenicity and perfusion. Longitudinal images of each testis in the medial, mid, and lateral portions and transverse images of the upper, mid and lower poles of each testis are then obtained. Each testicle should be measured consecutively in three dimensions (length, height, and width). Cineloops of each testis in the sagittal and transverse planes can provide more thorough diagnostic evaluation. Evaluation of the epididymides includes longitudinal and transverse images including the head, body, and tail. Color Doppler survey of the testicles and epididymides should be performed bilaterally with documentation of at least the capsular and centripetal arteries. Spectral waveforms that include both arterial and venous flow should be documented for each side. Color and spectral Doppler analysis should be optimized in attempts to depict low velocity venous flow. Specific evaluation for testicular torsion can be addressed by additional color Doppler imaging documenting several vascular planes and comparison with the contralateral, asymptomatic testis.

The scrotum should be surveyed for any extratesticular finding such as a hydrocele or scrotolith. Veins of the pampiniform plexus should be specifically evaluated as to diameter and augmentation with either the Valsalva maneuver or upright positioning of the patient. The scrotal skin should also be assessed for thickening, edema and symmetry.

Any extra- or intratesticular pathology (diffuse or focal) should be characterized by gray-scale ultrasonographic techniques and supplemental vascular imaging, as appropriate. Focal lesions can

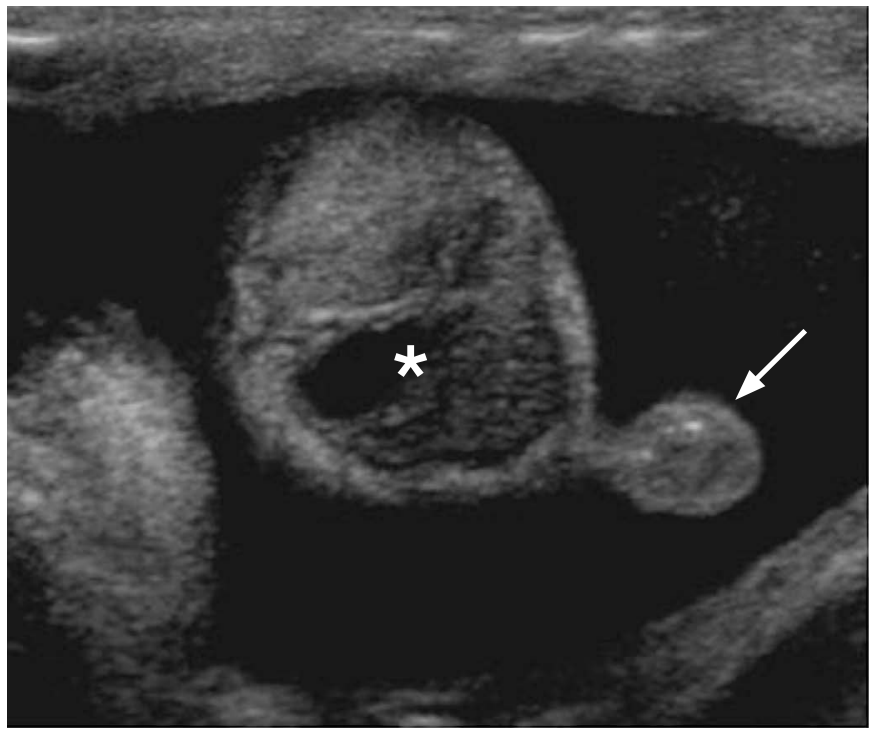

Fig. 4. Epididymal appendage of a 20-year-old male with testicular pain. Isoechoic, pedunculated, oval structure arising from the epididymal head (arrow). It represents a developmental remnant of the Wolffian (mesonephric) duct. An epididymal head cyst is incidentally found (asterisk).

be measured consecutively in three dimensions: length, height, and width. The pathology can be characterized ultrasonographically for the presence of cystic, solid, complex-cystic, or calcific components. Obtained images should be labeled with regards to the location of the lesion (upper, mid, and lower), image orientation (longitudinal and transverse) and the patient's position (supine, decubitus, and standing). Images obtained during performance of any maneuvers (i.e., Valsalva maneuver) should also be specifically labeled.

\section{Acute Scrotal Pain and Swelling}

\section{Epididymitis and Epididymo-orchitis}

A common cause of acute scrotal pain in adolescent boys and male adults is epididymitis, which is usually the result of an acute bacterial infection. Extension of the infection to the testis, then termed epididymo-orchitis (Fig. 5), occurs in about 20\% to $40 \%$ of cases due to direct spread of the infection [2]. Ultrasonographic findings of acute infection of the epididymis include an enlarged and hypervascular epididymis with an inhomogeneous echotexture, most often hypoechoic in appearance (Fig. 6). Color Doppler ultrasonographic evaluation has a sensitivity of almost $100 \%$ in detecting acute inflammation and is thus a well-established imaging technique for the diagnosis of epididymitis [3-5]. Associated findings include hydrocele or pyelocele, scrotal wall thickening, fistula formation and calcifications [6]. Abscess formation may complicate acute epididymitis and appears as an avascular 


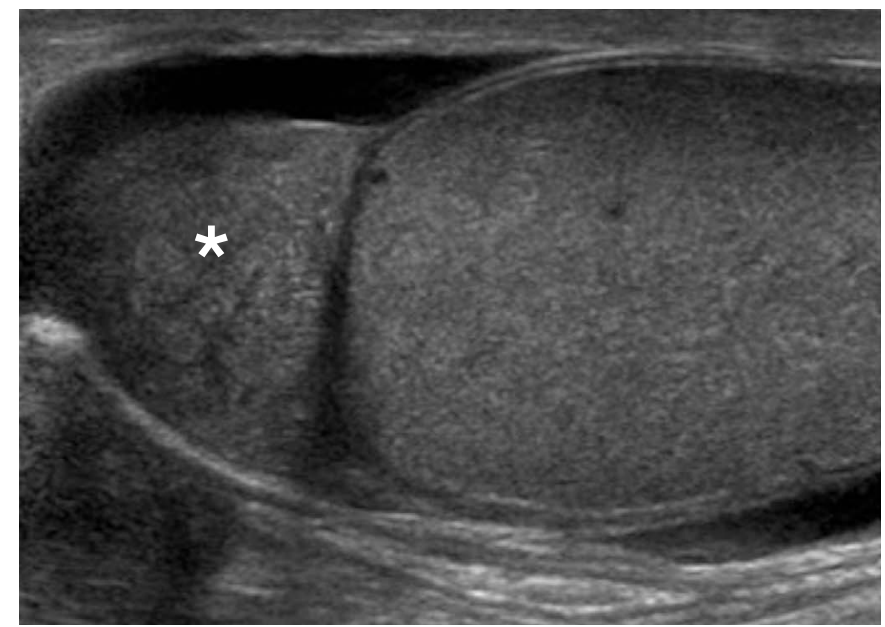

A

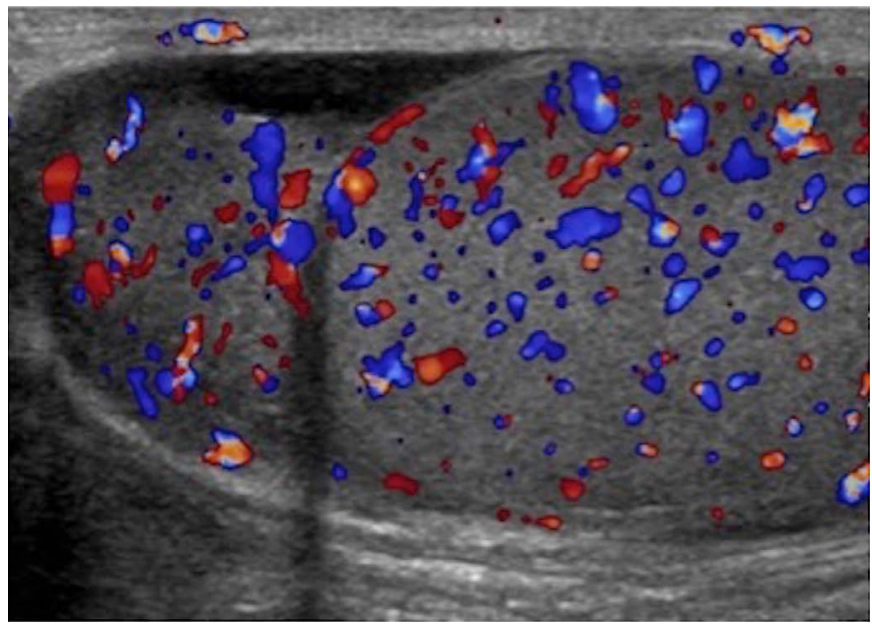

B

Fig. 5. A 48-year-old male with right testicular pain and swelling.

A. Longitudinal gray-scale ultrasonogram shows an enlarged heterogeneous epididymal head (asterisk) and an edematous and enlarged right testicle. B. Both demonstrate increased vascularity on color Doppler evaluation. Findings are consistent with epididymo-orchitis.

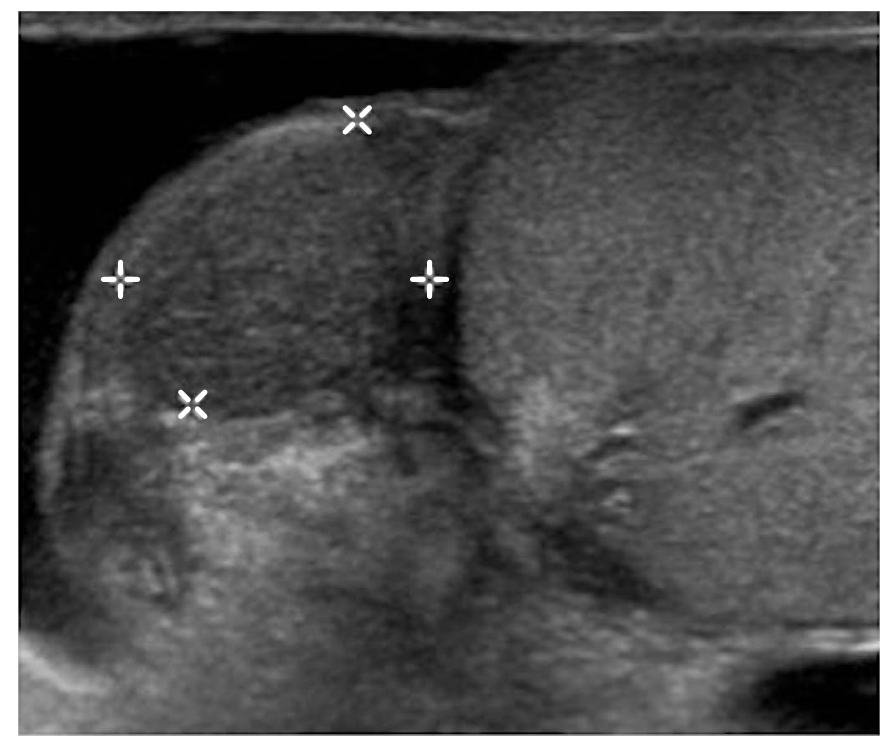

A

Fig. 6. A 48-year-old male with right testicular pain and swelling.

A, B. Gray-scale (A) and color (B) sonograms of the scrotum show a hypoechoic epididymis with markedly increased vascular flow, consistent with epididymitis.

hypoechoic area within the epididymis.

\section{Orchitis}

Isolated orchitis without involvement of the epididymis is rare and most commonly secondary to paramyxovirus infection (mumps) [2]. Orchitis most often appears as diffuse testicular involvement. However, it may only involve a focal area. Clinically, orchitis can present with only mild tenderness or evolve into a severe and febrile condition. Markedly increased flow on color Doppler, with an

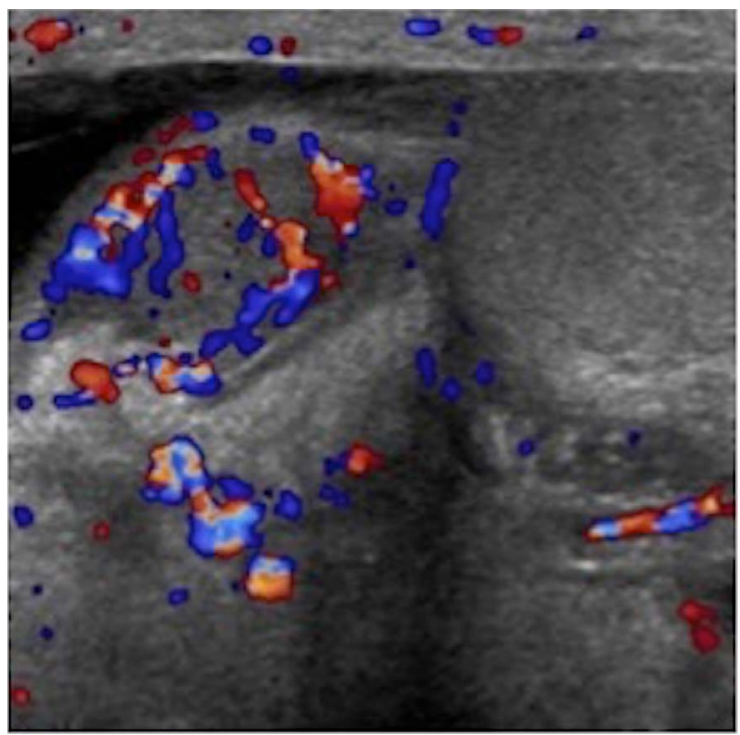

B 
it can occur at any age. Normally, the tunica vaginalis fixates the posterior aspect of the testicle. If the tunica vaginalis, however, joins high on the spermatic cord, it leaves the testicle free to rotate within the scrotal sac (bell clapper deformity). Most often, the bell clapper deformity is found bilaterally [7]. Thus, surgical orchiopexy is usually performed bilaterally even if only one testicle has torsed. A sensitive and specific sign for torsion is the so-called real-time whirlpool sign, which is characterized by a spiral twist or rotation of the spermatic cord (Fig. 7). Following rotation of the spermatic cord, blood flow to the testicle is compromised leading to severe ischemia and acute pain. Testicular torsion is a surgical emergency that requires prompt diagnosis and treatment. Ultrasonographic appearance of a torsed

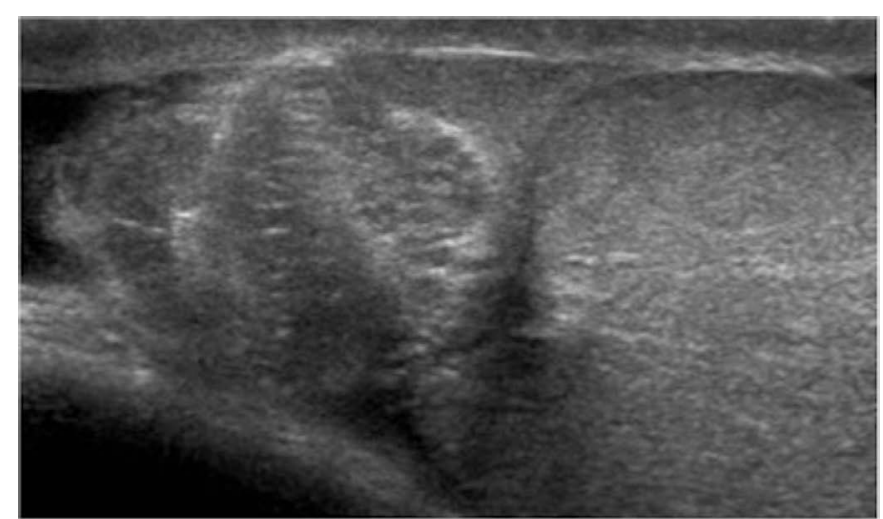

Fig. 7. A 20-year-old male with left testicular pain. Longitudinal gray-scale ultrasonogram of the superior aspect of the left testicle shows a spermatic cord that is twisted on itself, forming a heterogeneous mass in the region of head of epididymis, the socalled whirlpool sign.

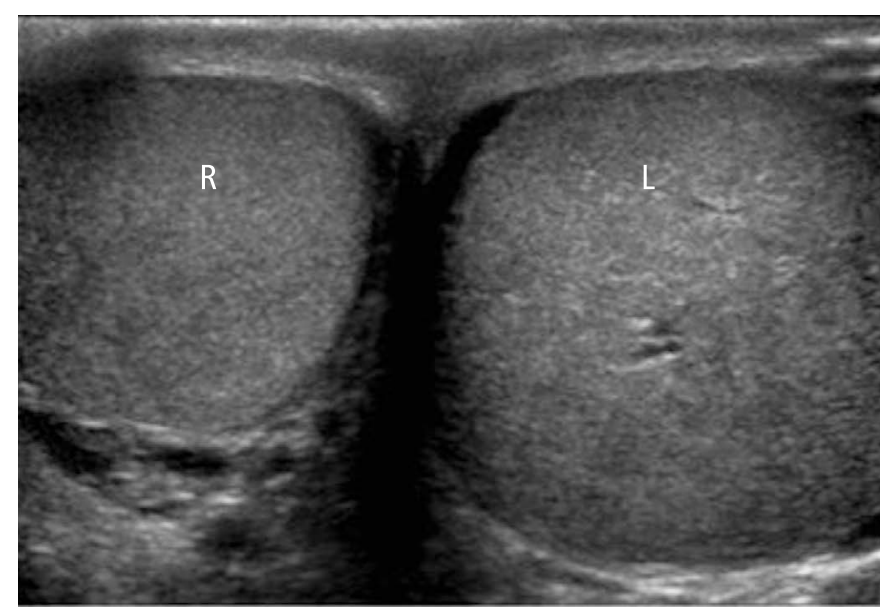

A testicle varies depending on the duration and degree of torsion. In the early phases, vascular compromise may only affect venous outflow and testicular echogenicity may appear normal. Progressive enlargement and heterogeneity of the testicle is seen in later phases due to edematous changes and arterial obstruction. Definitive diagnosis of complete testicular torsion is made when color Doppler fails to detects blood flow to the torsed testis with normal blood flow to the unaffected testis (Fig. 8). Surgical intervention is reported to be successful in $100 \%$ of cases if performed within 6 hours of symptom onset. Success rates, however, decrease to $0 \%-20 \%$ if symptoms have been present for 12-24 hours [8].

Intermittent testicular torsion should be considered in patients presenting with recurrent acute testicular pain with rapid onset and rapid spontaneous resolution. In these patients, surgery may be indicated in order to relieve pain and prevent future infarction of the testicle [9].

\section{Cellulitis}

Scrotal wall cellulitis is a cause of inflammatory scrotal wall edema. It is often seen in patients with diabetes, obesity or immunosuppression. Grayscale ultrasonography shows an increased scrotal wall thickness with a hypoechoic appearance and increased vascular flow on color Doppler evaluation. A scrotal wall abscess may form as a complication from scrotal wall cellulitis (Fig. 9). This should be suspected if a loculated fluid collection with irregular walls and low-level internal echoes is found.

\section{Vasitis}

Acute vasitis describes an inflammatory process of the vas deferens

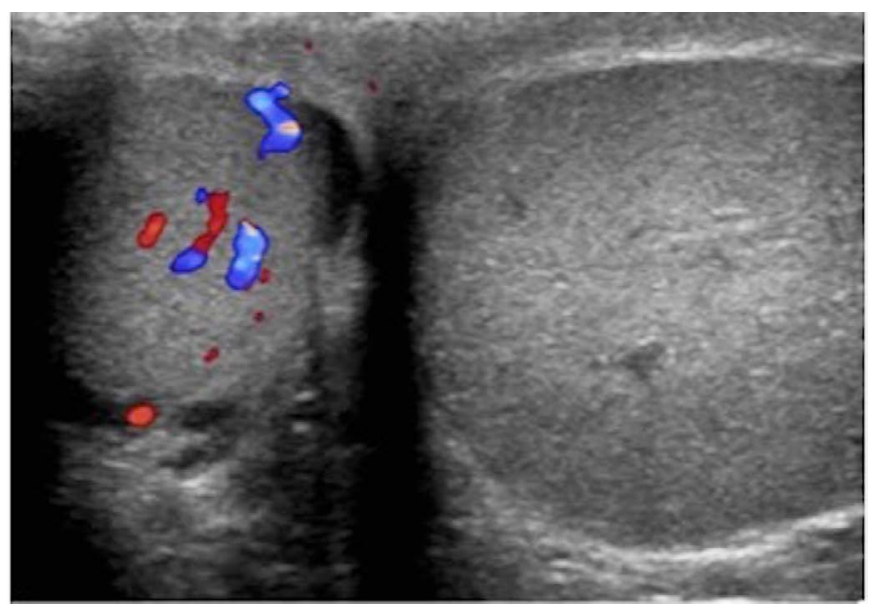

$B$

Fig. 8. A 20-year-old male with a history of severe left testicular pain for several hours.

A. Comparison view of both testicles demonstrates a normal right testicle (R) and an enlarged heterogeneous left testicle (L). B. Color Doppler evaluation shows flow in the right but not in the left testicle. Findings are consistent with complete testicular torsion. 


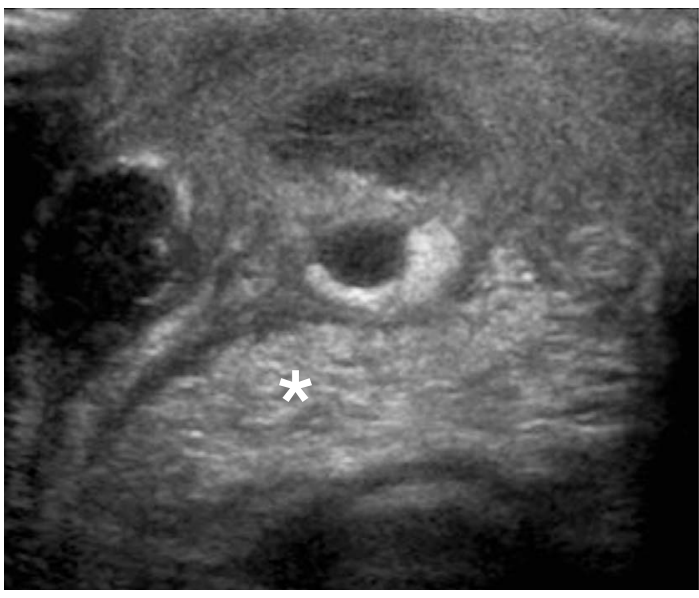

A

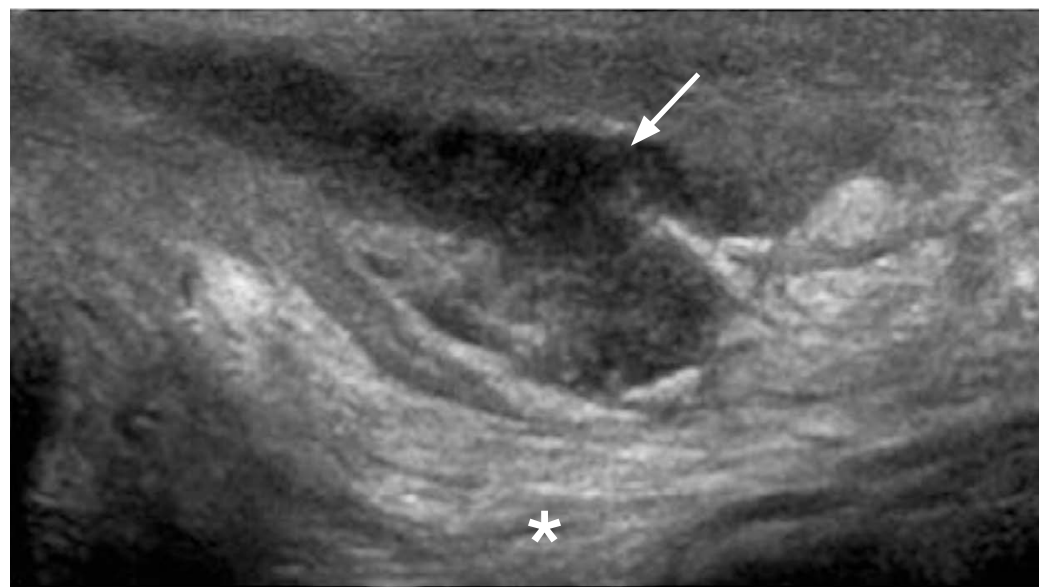

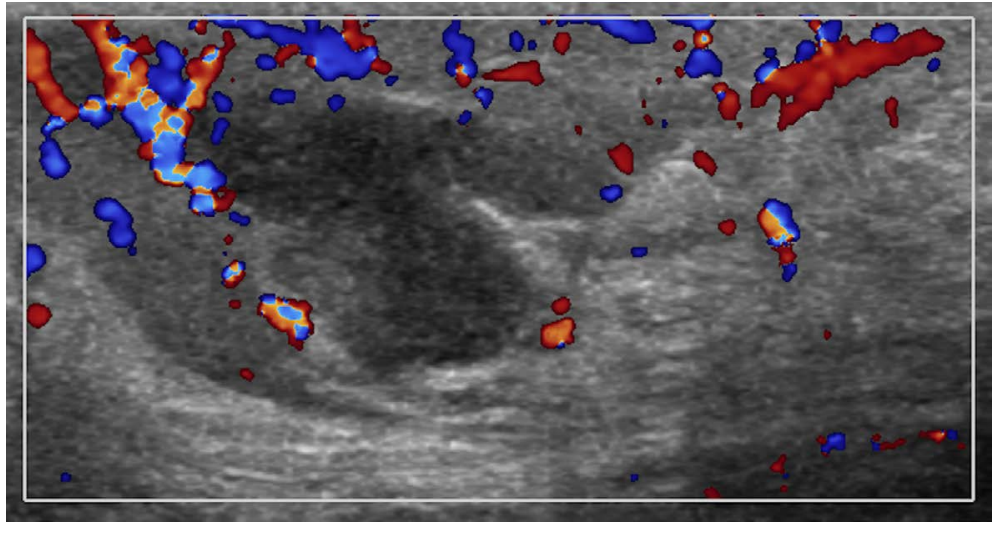

C
Fig. 9. Scrotal wall cellulitis with abscess in a 30-yearold male with scrotal swelling.

A, B. Marked diffuse thickening of the scrotal wall is noted on gray-scale ultrasonogram (asterisk) (A) with a loculated hypoechoic collection (arrow in B) demonstrating surrounding vascularity (C), which most likely represents a developing abscess. that usually results from retrograde spread of pathogens from the prostate, prostatic urethra or seminal vesicle. The most common pathogens are Haemophilus influenza and Escherichia coli [10]. Ultrasonography reveals a heterogeneously hypoechoic mass within the inguinal canal, possibly extending towards the scrotal segment, which demonstrates increased vascular flow (Fig. 10).

\section{Trauma}

Testicular trauma can manifest as fluid collections (hematocele, hydrocele, or hematoma), testicular disruption (fracture or rupture) or vascular injury. Ultrasonographic evaluation of an injured testicle is crucial in determining conditions that require immediate surgical intervention. Heterogeneous appearance of the testicle, irregular contour abnormality with or without visualized interruption of the tunica albuginea, and loss of focal or diffuse vascular flow are signs consistent with testicular rupture (Figs. 11, 12) [11,12]. Emergent surgical repair performed within 72 hours has a high testicular salvage rate $(>80 \%)[13,14]$.

A discontinuity in the usual testicular parenchyma is considered a testicular fracture. It is identified as a hypoechoic, linear stripe within the testicle that does not demonstrate vascularity. Visualization of such a fracture line has only been reported in $17 \%$ of cases [15]. Testicular fractures may but do not necessarily have to be associated with a tunica albuginea rupture. Post-traumatic hematomas can be seen in the testicle or in extratesticular locations such as the epididymis, scrotal wall or between the testicles. Acute hematomas have a hyperechoic appearance on ultrasonography. Over time, the hematoma appears increasingly hypoechoic with potentially complex and cystic components. Color Doppler ultrasonography demonstrates no flow within these lesions. Hematoceles are blood collections between the two layers of the tunica vaginalis, which appear echogenic in the acute phase. Older hematoceles appear more hypoechoic and may demonstrate fluid-fluid levels or septations.

\section{Palpable Lumps and Incidental Findings}

\section{Epididymal Cyst}

Epididymal cysts can occur anywhere within the epididymis and appear as well-circumscribed anechoic lesions (Fig. 13). The cysts 


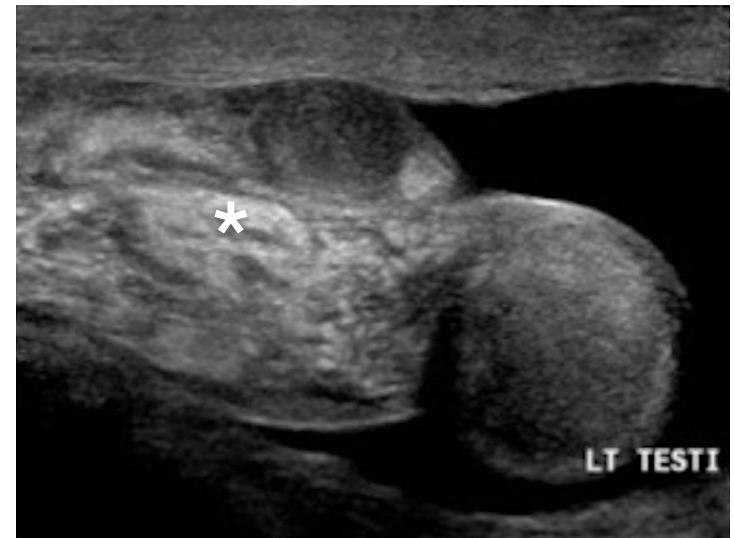

A

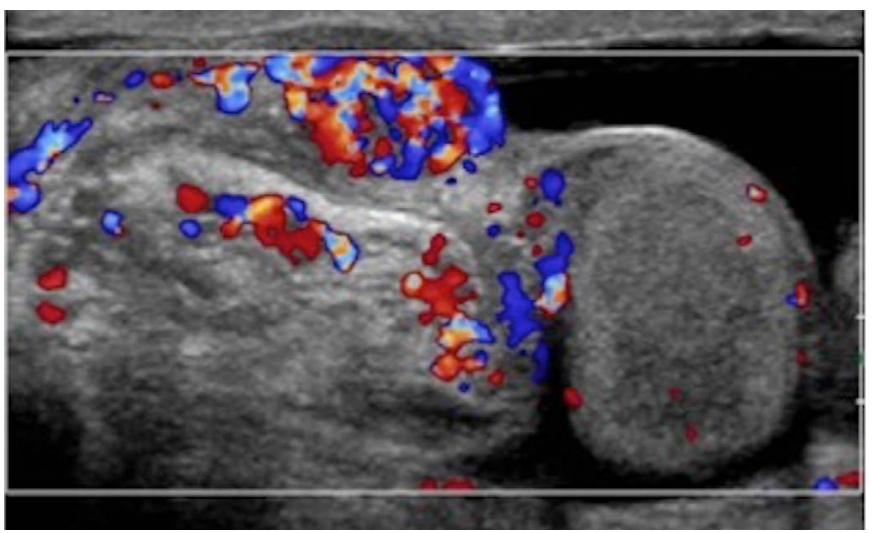

C

Fig. 10. A 36-year-old male with diffuse left testicular pain.

A, B. Gray-scale ultrasonogram shows a complex tubular structure superior to the left testicle (asterisk in A) with extension along the spermatic cord into the left inguinal canal (B). C, D. Increased vascularity is noted. The findings are consistent with vasitis.

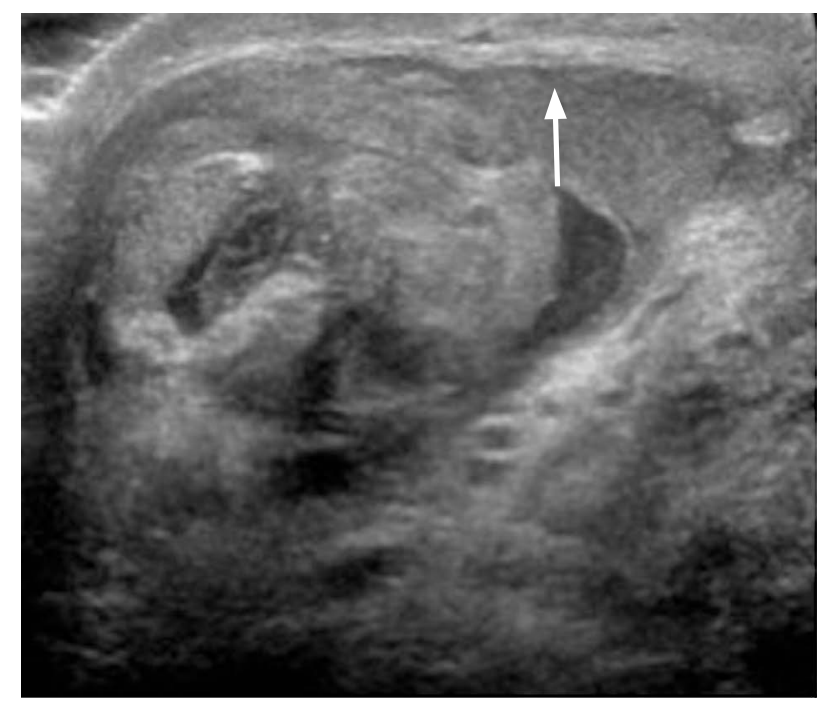

A

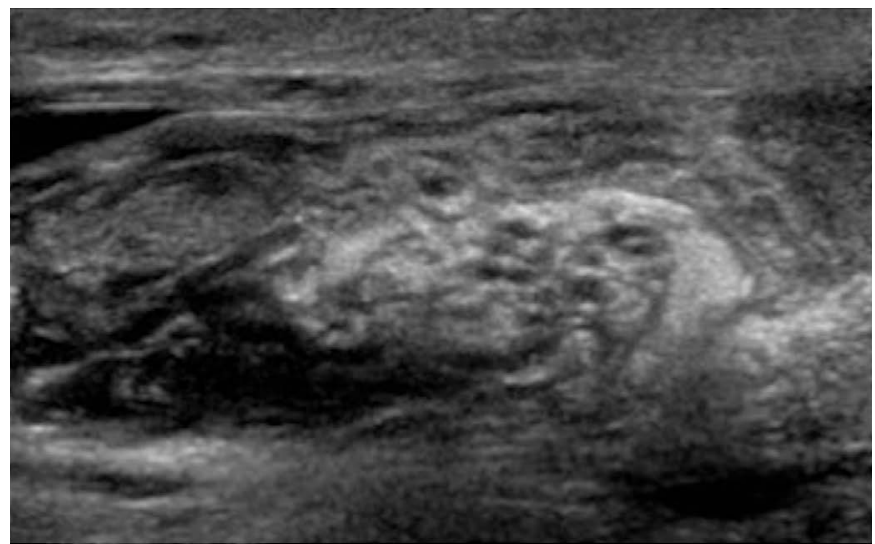

B

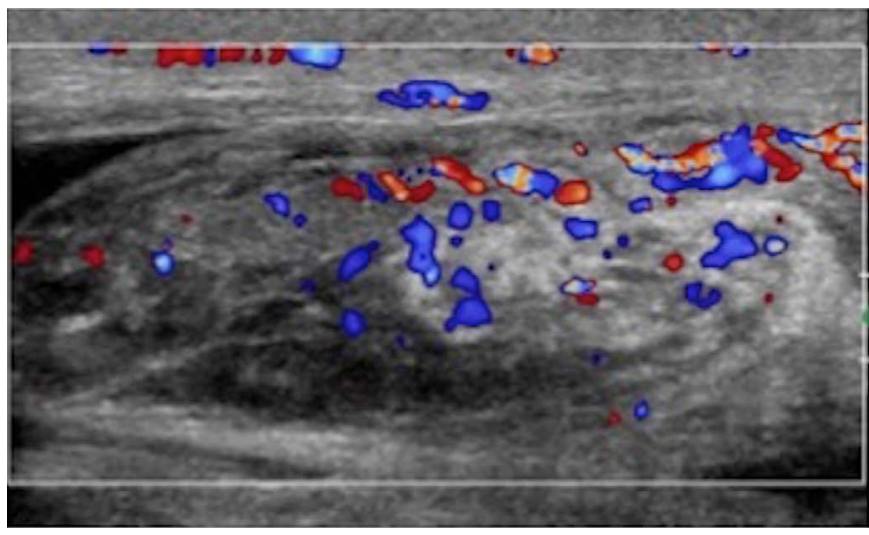

D 


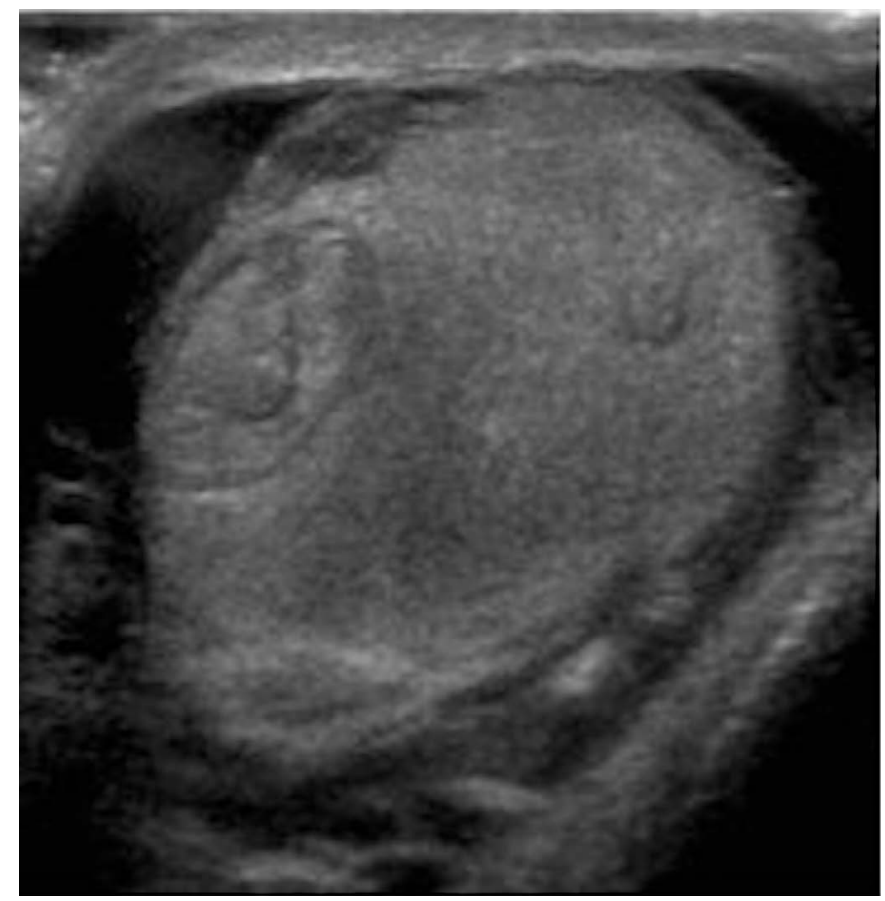

A

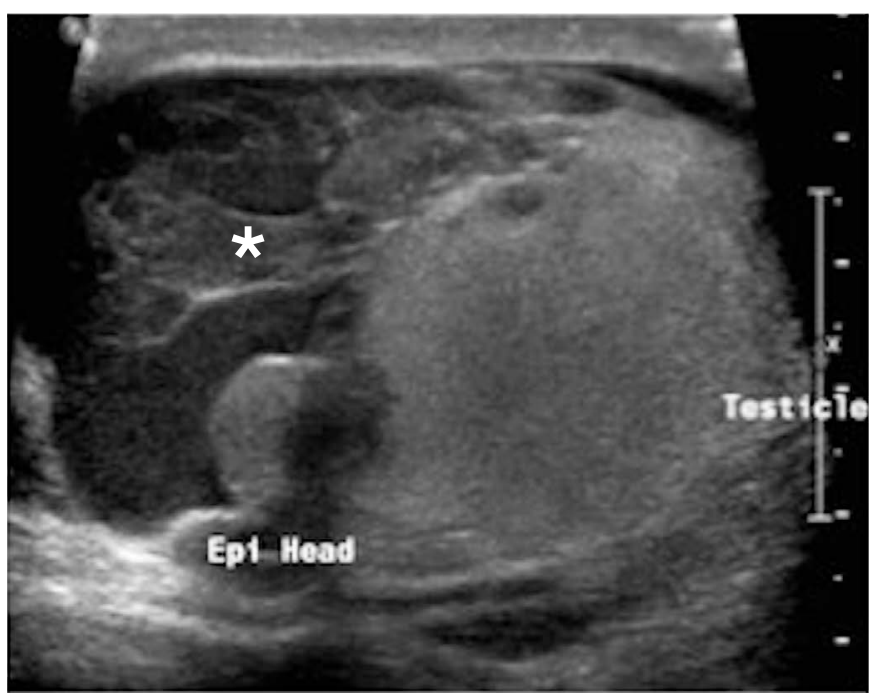

B

Fig. 12. A 24-year-old male with left testicular trauma.

A, B. The left testicle demonstrates heterogeneous echotexture with irregular contours (A) and an associated complex left hydrocele (asterisk) (B). Findings are consistent with posttraumatic testicular hematoma, capsular rupture, and associated hematocele.

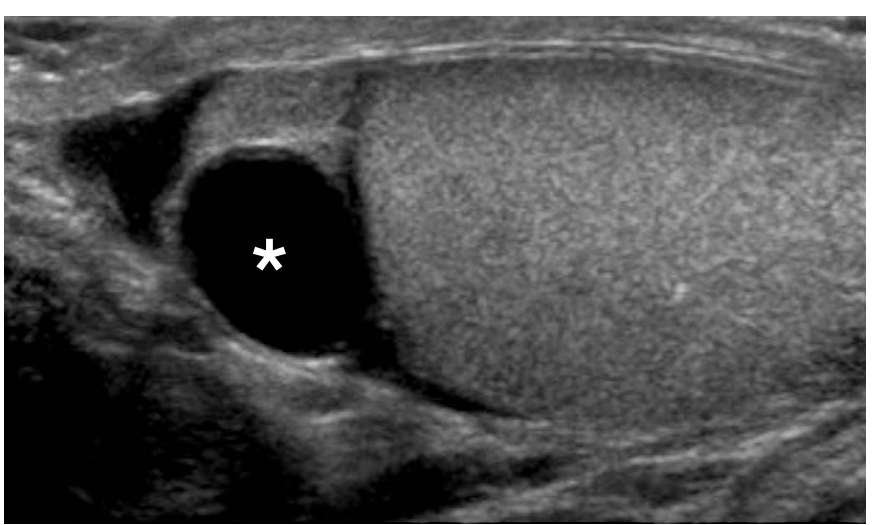

Fig. 13. Epididymal cyst in a 32-year-old male with scrotal pain. Gray-scale ultrasonogram shows a well-circumscribed anechoic lesion (asterisk) in the epididymal head that does not demonstrate internal vascularity.

demonstrate posterior acoustic enhancement due to their clear serous fluid content. Unless symptomatic, these cysts are clinically irrelevant and no treatment is necessary.

\section{Testicular Cyst}

Simple cysts in the parenchyma of the testicle are usually incidental findings. They are solitary, anechoic, well circumscribed, round to oval lesions with increased through-transmission [16] and measure from 2 to $20 \mathrm{~mm}$. Their etiology is often idiopathic; however, they may represent sequelae from prior trauma or inflammation. Careful examination for solid or mural components is advised in order to not miss a potentially malignant cystic lesion.

\section{Epidermoid Cyst}

Epidermoid cysts often present as a non-tender small testicular nodule. They represent the most common benign testicular masses $(1 \%-2 \%$ of testicular tumors) and have no malignant potential. Epidermoid cysts are often referred to as keratocysts due to their characteristic intraluminal keratin contents. The echogenic keratin can lead to a solid appearance on ultrasonography. Doppler evaluation, however, does not demonstrate internal vascularity (Fig. 14). Epidermoid cysts show different ultrasonographic appearances depending on their maturation. A lamellated pattern of alternating hypoechoic and hyperechoic layers forming an onion-ring/skin pattern is a classic presentation of a maturing epidermoid cyst $[17,18]$. This appearance grossly corresponds to the multiple intraluminal layers of keratin within the cyst $[2,17,19]$. Despite being a benign lesion, epidermoid cysts can often not be distinguished from malignant neoplasms such as teratomas, which may present with a similar ultrasonographic appearance. In the presence of an avascular lesion with typical ultrasound features and negative 


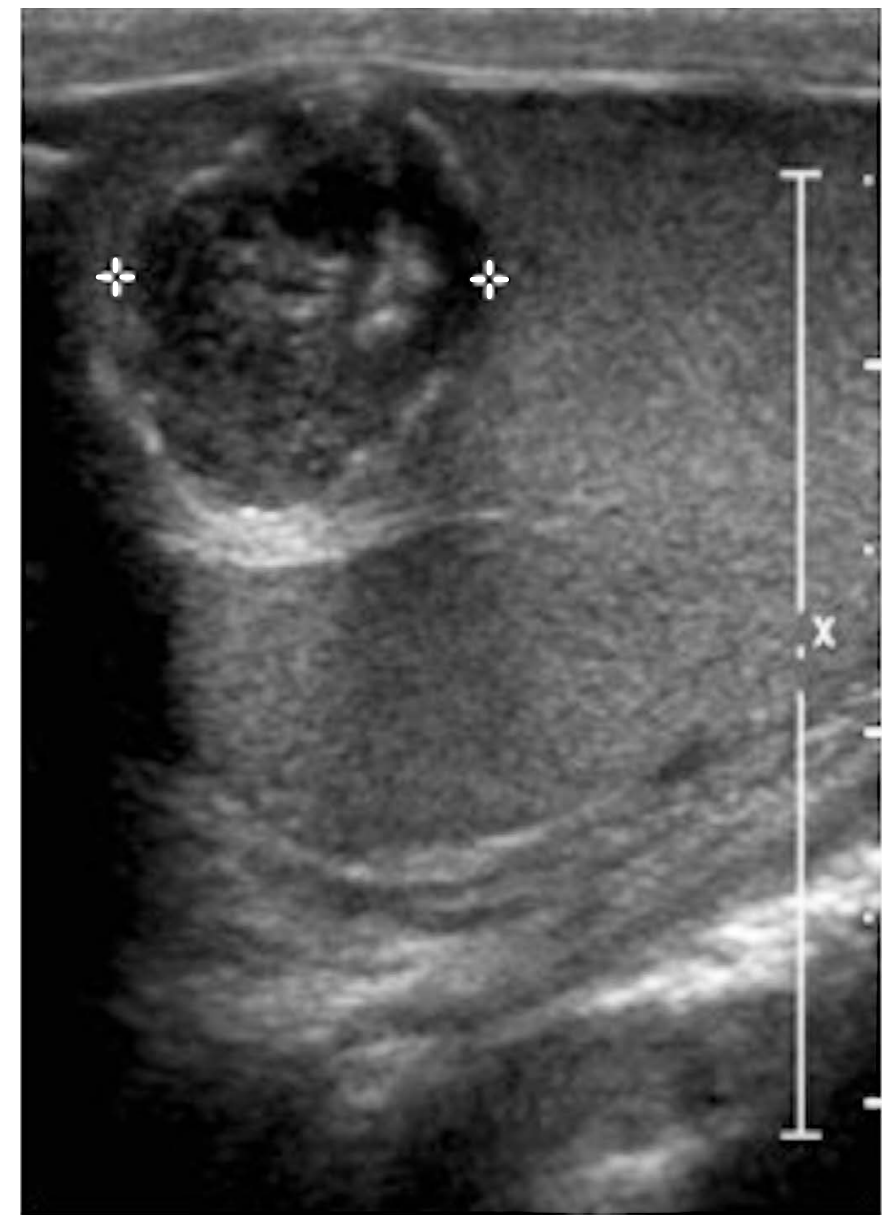

A

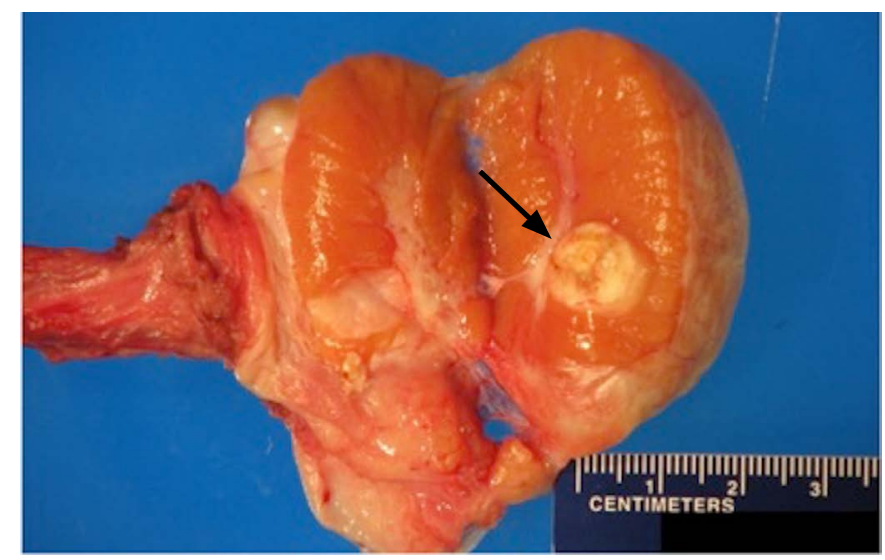

C

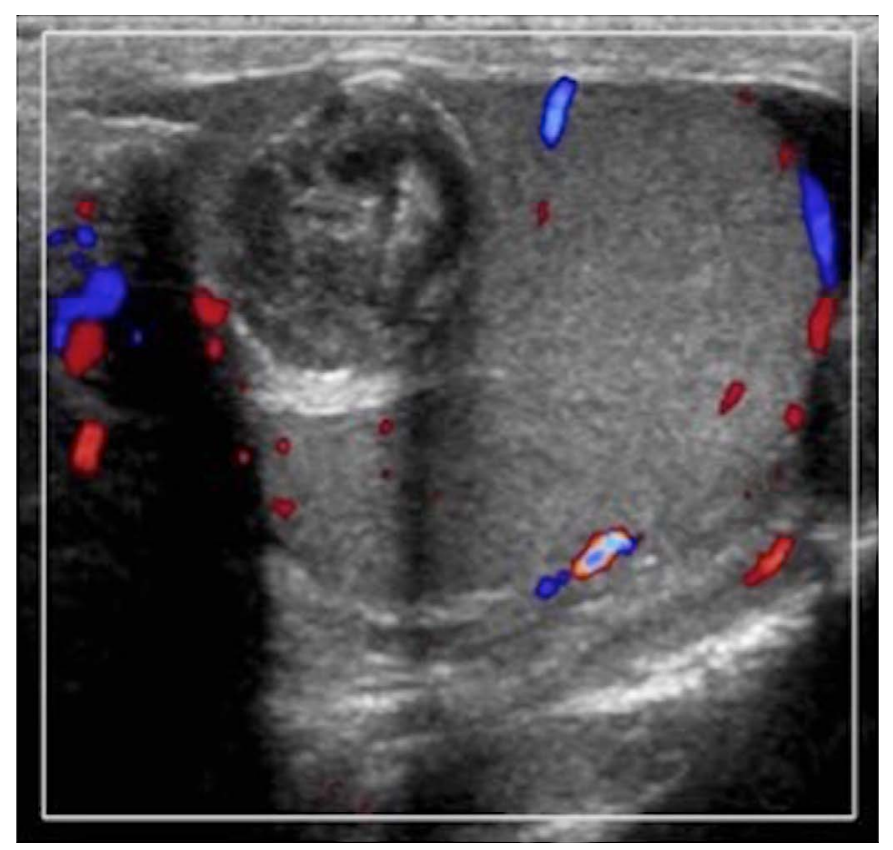

B

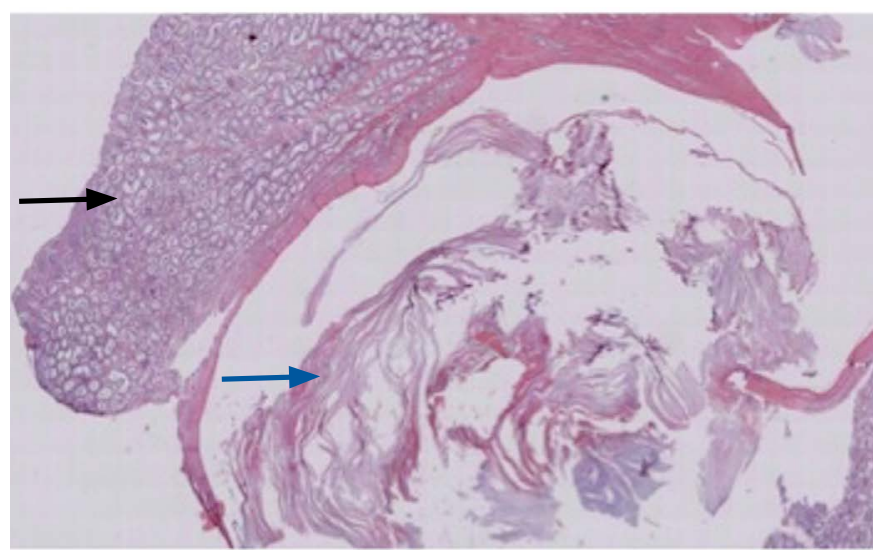

D

Fig. 14. Epidermoid cyst in a 34-year-old male with scrotal pain.

A, B. Complex solid and cystic-appearing lesion in the testicle does not demonstrate internal vascularity. The solid component of the cyst corresponds to its keratin contents on the surgical specimen. C. Macroscopic pathology specimen shows a firm, well-encapsulated and delineated white/yellow lesion in the testicular parenchyma. The surrounding testicular tissue is unremarkable. The yellowish content within the cystic structure (arrow) represents the keratin contents previously identified on ultrasonography. D. Testis with epidermoid cyst $(\mathrm{H} \& \mathrm{E}, \times 1)$ : a cystic lesion with keratinaceous debris is seen in the center (blue arrow). Surrounding the lesion, unremarkable seminiferous tubules (black arrow) are seen. There is no evidence of malignancy or intratubular germ cell neoplasia. 
tumor markers, testicular enucleation can be considered rather than orchiectomy [19-22].

\section{Spermatocele}

Spermatoceles almost always arise in the epididymal head and are caused by cystic dilatation of the tubules of the efferent ductules [23]. Ultrasonographically they are indistinguishable from epididymal cysts. However, spermatoceles tend to be larger in size and may present as a multilocular cystic lesion with internal echoes representing proteinaceous fluid and spermatozoa [24]. Some literature reports a higher incidence of spermatoceles in patients after vasectomy, whereas epididymal cysts are reported to be more common in the general population [25-28].

\section{Varicocele}

A varicocele is seen in approximately $15 \%$ of adult men, making it the most common palpable mass of the spermatic cord [29]. Varicoceles form due to impaired drainage of blood from the spermatic cord causing abnormal dilatation of the pampiniform plexus $[19,30]$. Cases of idiopathic varicocele are simply caused by incompetent venous valves. However, secondary varicoceles are due to an increase of pressure in the spermatic veins caused by an extratesticular process such as cirrhosis, hydronephrosis or an abdominal/pelvic mass $[2,19]$. Clinically, palpation of the scrotum

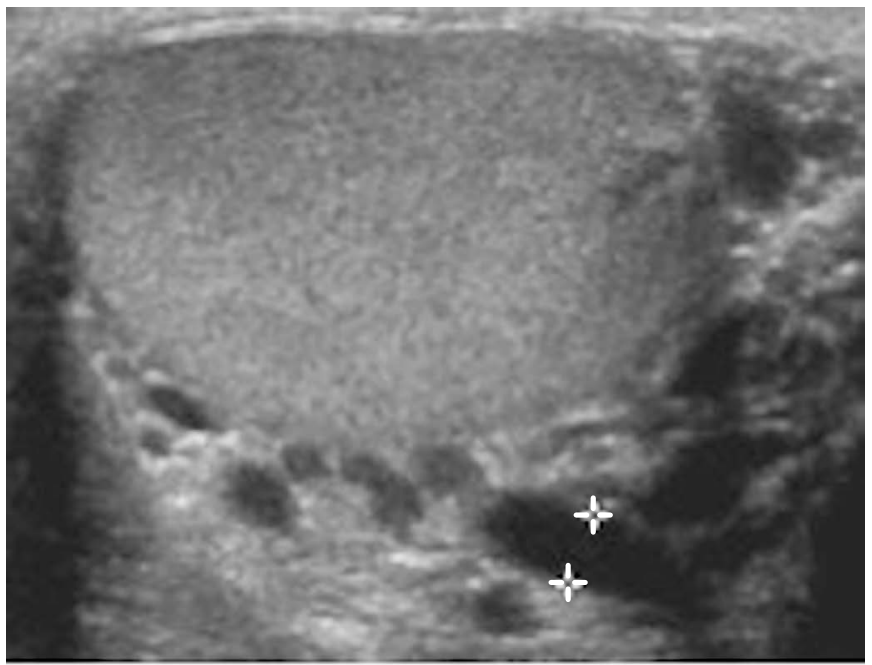

A

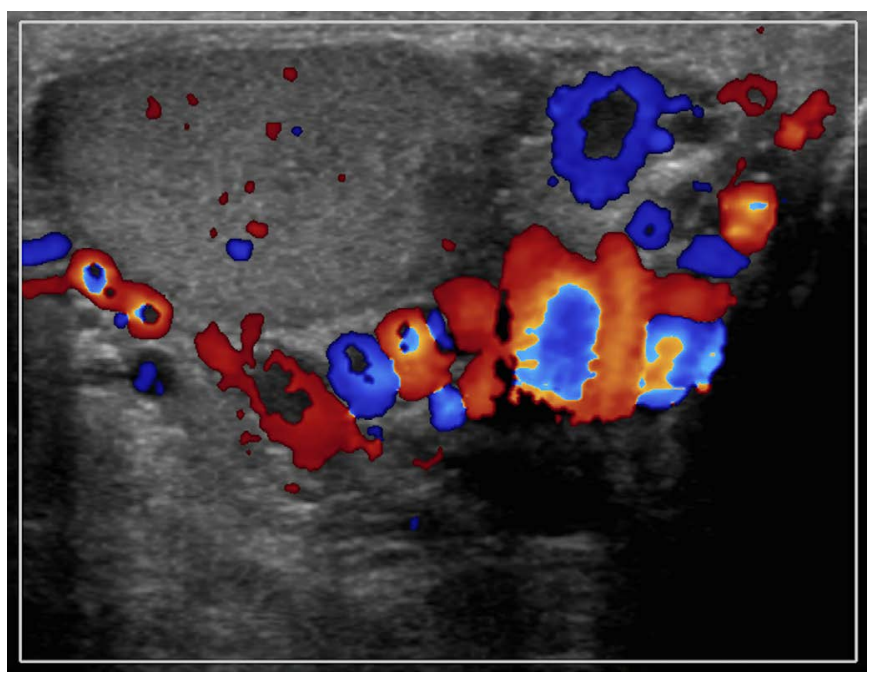

C

Fig. 15. Varicocele in a 33-year-old male with scrotal swelling. A-D. Ultrasonogram reveals several tubular structures greater than $3 \mathrm{~mm}(A, B)$ with markedly increased vascular flow on color Doppler evaluation on resting $(C, D)$. 


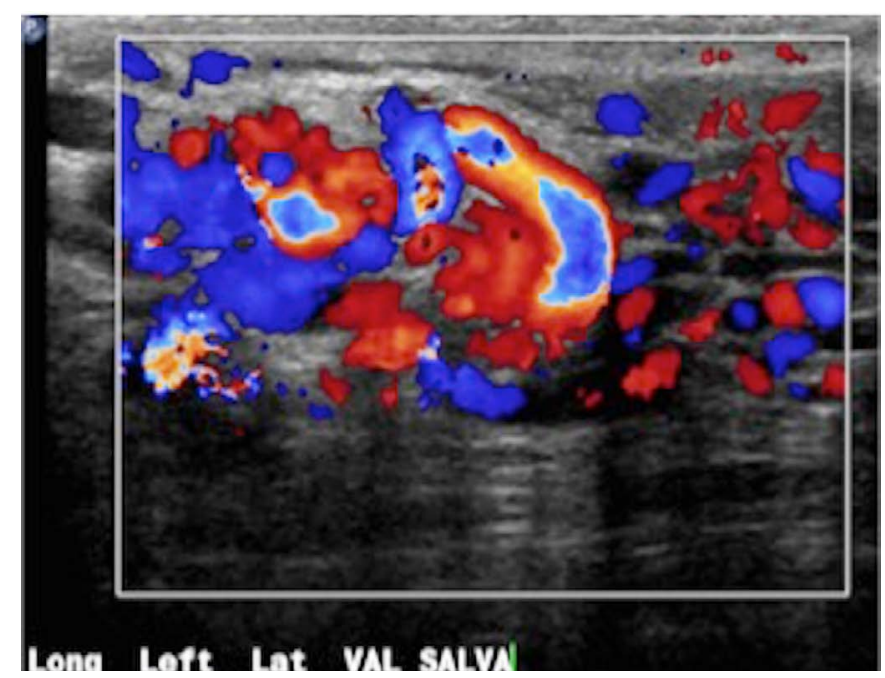

$\mathrm{E}$

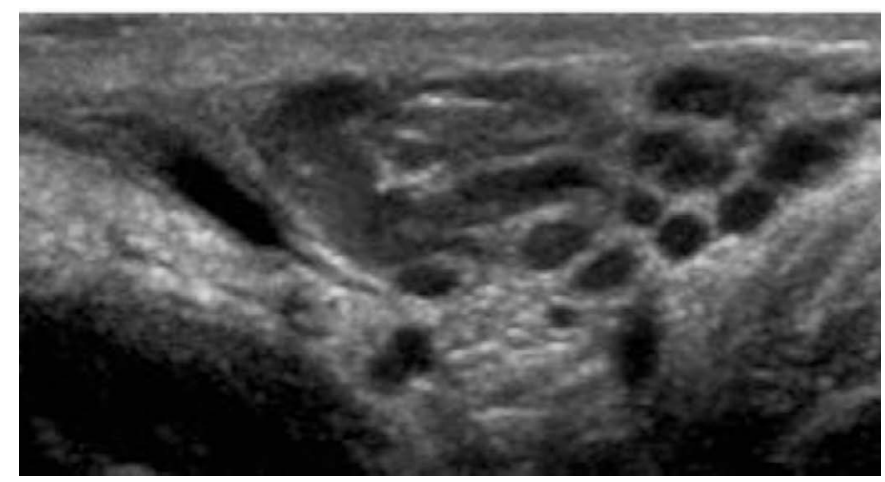

G

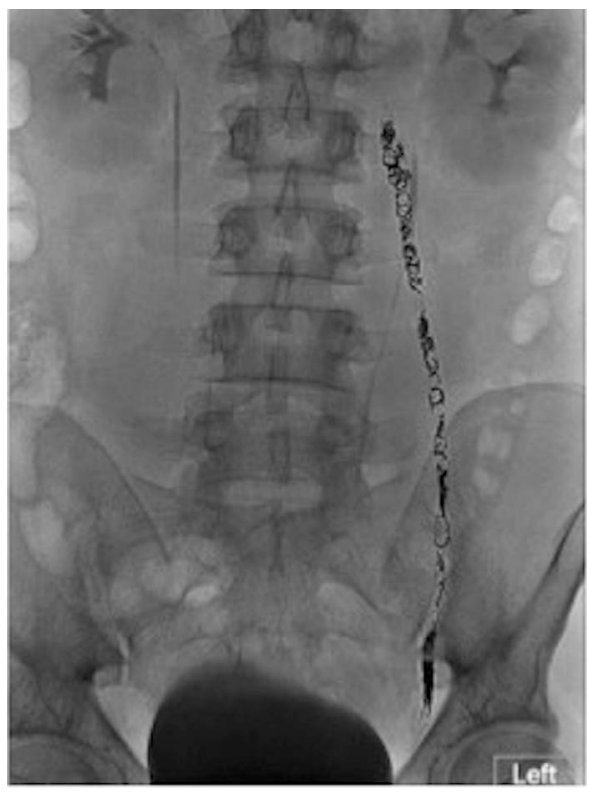

$\mathrm{F}$

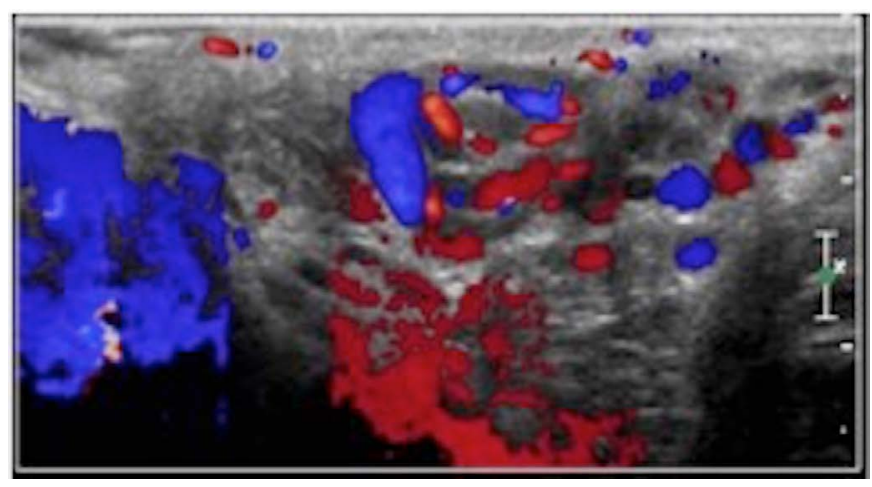

$\mathrm{H}$

Fig. 15. E. Increased vascular flow with engorgement of the veins is seen during Valsalva maneuver. F. The patient underwent left gonadal vein embolization with multiple endovascular coils seen in the region of the left gonadal vein on a subsequent abdominal radiograph. $G, H$. Follow-up ultrasonography demonstrates reduction in size of the varicoceles $(\mathrm{G})$ with somewhat decreased vascular flow (H).

may reveal a mass that is often described as a "bag of worms." It shows multiple hypo- or anechoic tubular structures greater than 2 to $3 \mathrm{~mm}$ in diameter. Occasionally detected low-level echoes within these veins result from slow blood flow. During the Valsalva maneuver the varicocele may enlarge and it may demonstrate flow reversal on color Doppler imaging depending on grade. Varicocele embolization has been shown to be as effective as surgical ligation (Fig. 15).

Varicoceles are most commonly found on the left side. The left testicular vein is longer and connects to the left renal vein at a $90^{\circ}$ angle, resulting in increased pressure compared to the right testicular vein, which drains directly into the IVC. A newly diagnosed unilateral right-sided varicocele raises concerns of a secondary cause such as pelvic or abdominal malignancy. Compression of the left renal vein by the superior mesenteric artery, sometimes referred to as the Nutcracker syndrome, can also be a non-malignant cause of left-sided varicoceles, with increased pressures transmitted into the left pampiniform plexus [31].

\section{Hydrocele}

A hydrocele is a large collection of fluid between the visceral and parietal layers of the tunica vaginalis and the most common cause of painless scrotal swelling [32]. Of note, a small amount of serous fluid between the layers of the tunica vaginalis is a benign finding and should not be mistaken for a hydrocele. Hydroceles can be congenital or acquired. Congenital hydroceles are due to a patent processus vaginalis, which permits accumulation of peritoneal fluid in the scrotal sac. Acquired hydroceles are either idiopathic due to 


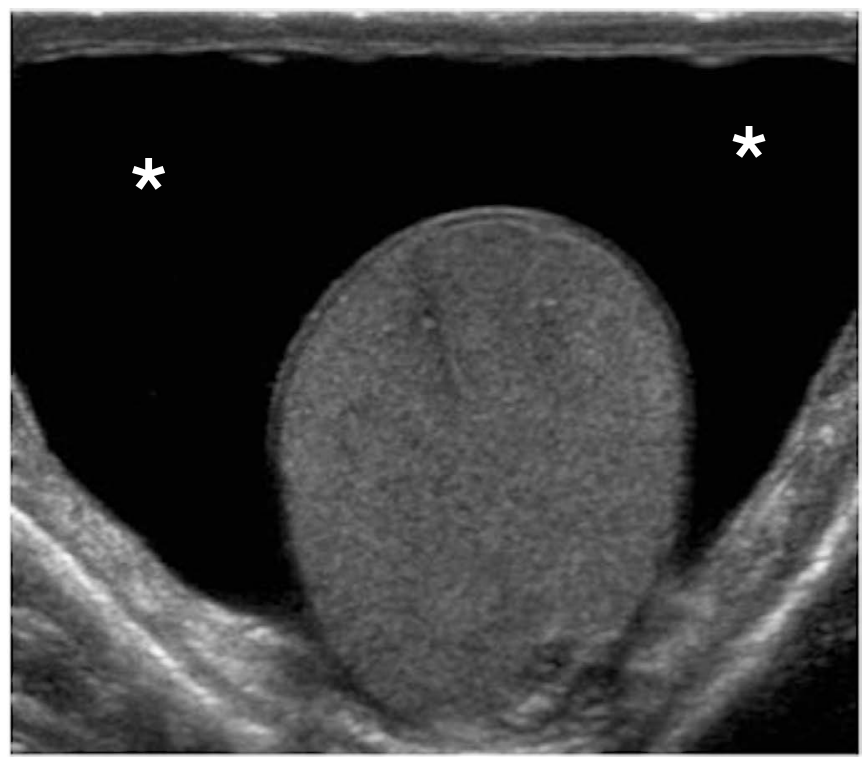

Fig. 16. Hydrocele in a 28-year-old male with scrotal swelling. Transverse ultrasonogram of the scrotum shows an anechoic fluid collection surrounding the testicle (asterisks).

overproduction or impaired absorption of serous fluid. They may be secondary due to infection, torsion, trauma, or tumor $[2,19]$.

Hydroceles present as anechoic fluid collections with increased through-transmission that surround the anterolateral aspect of the testicle. Internal echoes within the fluid collection can sometimes be appreciated and are related to protein or cholesterol content (Fig. 16) $[2,19,33,34]$.

\section{Microlithiasis}

Testicular microcalcifications are usually found incidentally and are only seen in about $5 \%$ of males between the age of 17 and 35 [35]. Ultrasonography demonstrates intra-tubular calcifications of 2-3 mm in size as multiple, non-shadowing small echogenic foci that are randomly distributed throughout the testicle (Fig. 17) $[36,37]$. Five or more calcified foci per transducer field in one testis is considered abnormal. In $18 \%$ to $75 \%$ of cases, microlithiasis has been associated with testicular neoplasms (Fig. 18) [38,39]. The current literature does not provide any proof that testicular microcalcifications can be regarded as a premalignant condition or causative agent. Patients diagnosed with microcalcifications should undergo annual ultrasonography screening, especially when symptomatic. However, some literature suggests that intensive screening in asymptomatic patients may not be cost-effective and would do little to improve outcomes associated with testicular cancer [40-42].

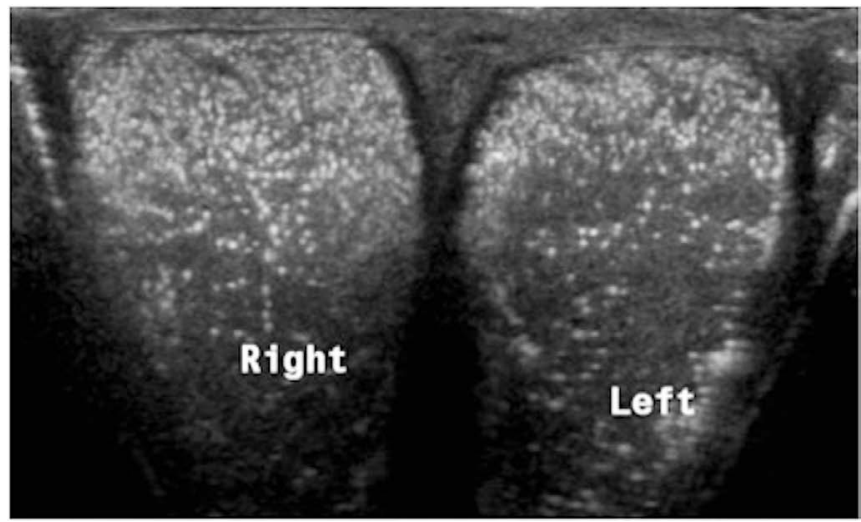

Fig. 17. Testicular microcalcifications in a 35-year-old patient with scrotal discomfort. Comparison view of both testicles demonstrates multiple small echogenic foci within the testicular parenchyma. No underlying mass was identified.

\section{Scrotolith}

Scrotoliths, scrotal pearls or scrotal calculi are mobile calcifications in the scrotum and represent calcified loose bodies that result from torsion of the appendix epididymis/appendix testis or reactive fibrous proliferation during intrascrotal inflammation $[33,43]$. On ultrasonography, they appear as free-floating, echogenic foci measuring up to $10 \mathrm{~mm}$ with posterior acoustic shadowing and are located outside of the testicle (Fig. 19). The presence of a small amount of fluid or a hydrocele (50\% association) facilitates their ultrasonographic identification. Overall, these calcifications have no clinical significance.

\section{Adenomatoid Tumor}

Adenomatoid tumor is a benign neoplasm that most commonly arises from the epididymal tail [44]. Accounting for approximately $30 \%$ of extratesticular tumors, it is the most common solid neoplasm of the epididymis. Ultrasonography assessment reveals a well-circumscribed hypoechoic, rounded mass with a usually homogeneous echotexture. Because the ultrasonographic appearance can vary, the tumor is often resected $[28,44]$. There are currently no documented cases of recurrence or metastatic spread following excision [45].

\section{Germ Cell Tumors}

Germ cell tumors account for approximately $90-95 \%$ of all testicular tumors. They are further divided into seminoma and nonseminomatous germ cell tumors (NSGCTs), which is important in 


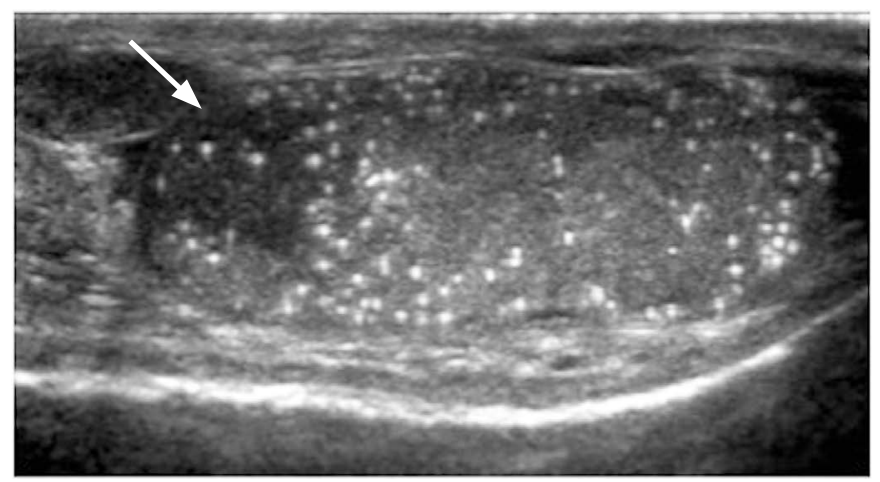

A

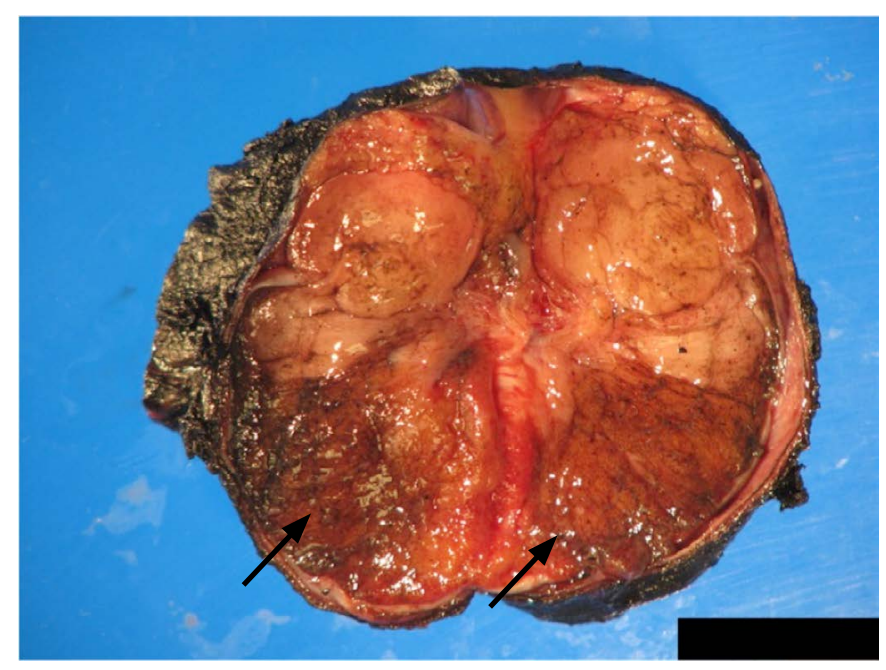

C

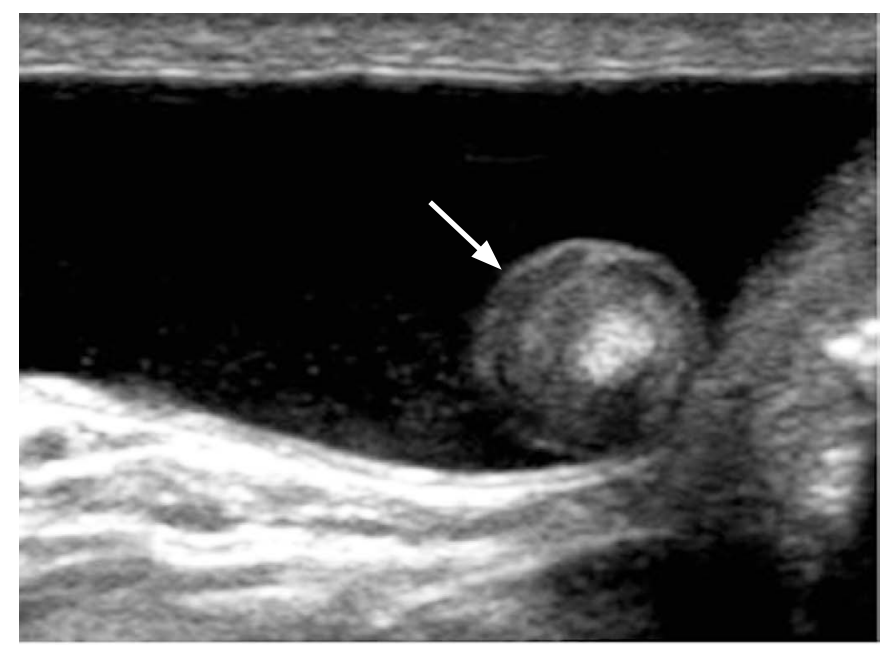

A

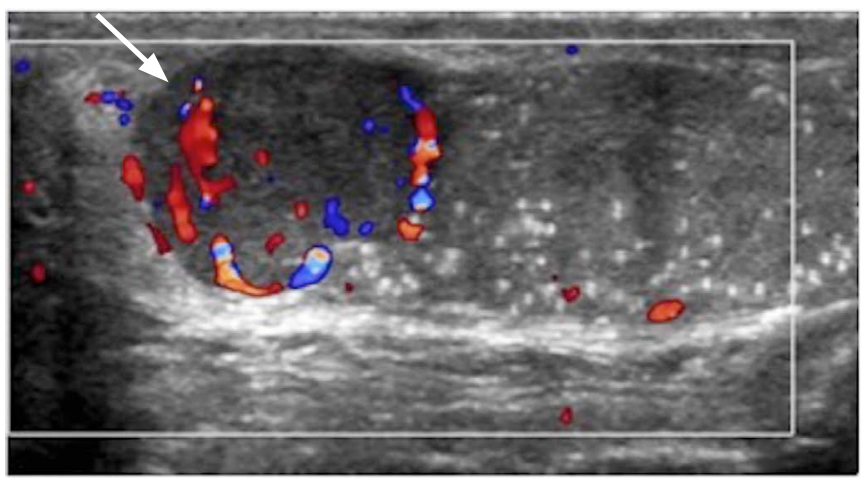

B

Fig. 18. Microcalcifications associated with a testicular mass in a 32-year-old male with a non-tender left scrotal mass.

A, B. Ultrasonogram reveals microcalcifications throughout the heterogeneously echogenic testicle (A) and presence of a hypoechoic vascular lesion (arrow in A and B) arising from the superior aspect of the left testicle (B). The left testicle was subsequently resected and pathology evaluation identified the mass as a seminoma. C. Macroscopic pathology specimen shows the entire left testicle cut in half. A solid, firm greyish-colored mass measuring $2.0 \times 1.8 \times 1.8 \mathrm{~cm}$ (arrows) is located at the superior pole of the testicle abutting the epididymis and tunica albuginea.

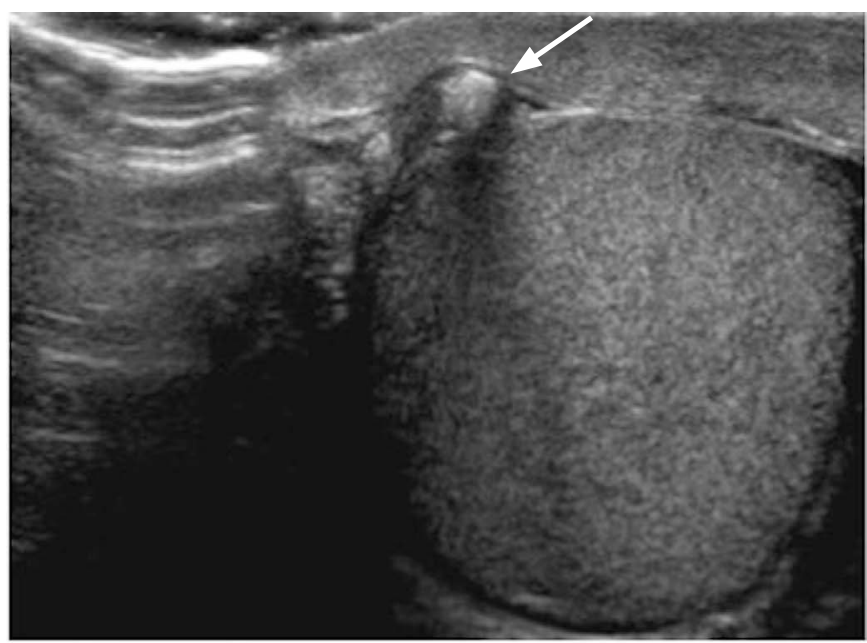

B

Fig. 19. Scrotal pearls in a 28-year-old male and a 32-year-old male with incidental findings.

A, B. Longitudinal (A) and transverse (B) gray-scale ultrasonograms show echogenic foci at the anteromedial aspect of the testicle with posterior acoustic shadowing (arrow). 
determining treatment and prognosis. Among germ cell tumors, seminomas are the most common testicular malignancy (35\%-50\% of all cases) [46]. Because of their high sensitivity to radiation and chemotherapy, seminomas have the best prognosis among germ cell tumors. On ultrasonography, seminomas appear as hypoechoic solid lesions with internal blood flow, which can range from small lesions to large masses that replace the entire testicle (Fig. 20) [47]. Metastases to the brain, lung and retroperitoneal lymph nodes via hematogenous and lymphatic spread are seen in approximately $25 \%$ of patients at the time of presentation [48].

Overall, NSGCTs are considered the most common testicular neoplasm (60\% of cases) [36]. Pure NSGCTs are rare and most

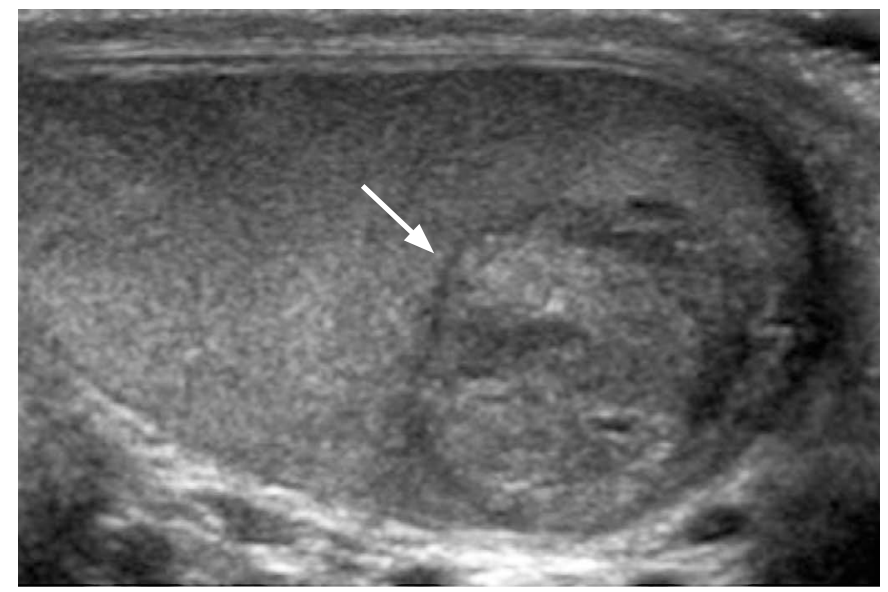

A

Fig. 20. A 26-year-old male with a painless right testicular mass.

A, B. Longitudinal gray-scale ultrasonogram of the right testicle (A) shows a heterogeneous mass (arrow), with internal vascular flow on color Doppler imaging (B). The patient subsequently underwent right orchiectomy. Histologically the mass was found to represent a seminoma.

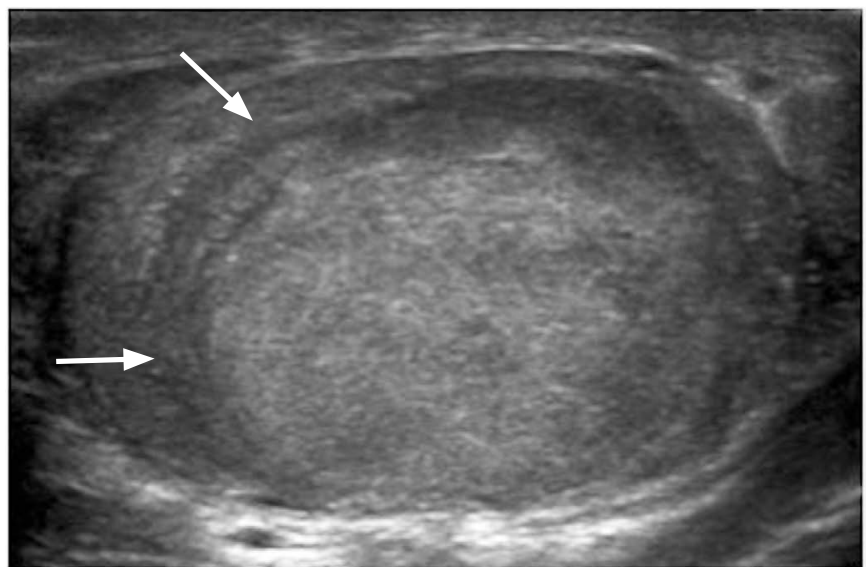

A

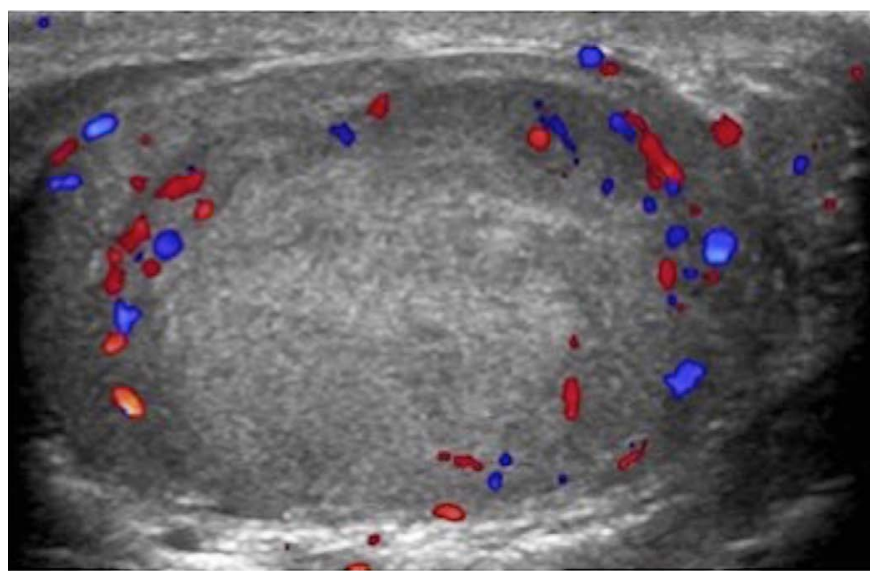

B often encountered in the pediatric population [46]. They include teratoma, embryonal cell carcinoma, choriocarcinoma, yolk sac tumor and mixed subtypes $[2,46]$. The majority of NSGCTs manifest with advanced disease [49].

NSGCTs present ultrasonographically as heterogeneous and cystic masses with irregular margins (Figs. 21, 22). Echogenic foci within the mass may be seen, which can represent calcification, hemorrhage, or fibrosis. In some cases, the tumor may present with increased vascularity mimicking acute testicular inflammation. However, the underlying testicular parenchyma demonstrates an inhomogeneous appearance rather than a regular echotexture. Ultrasonographic follow-up evaluations are recommended to help

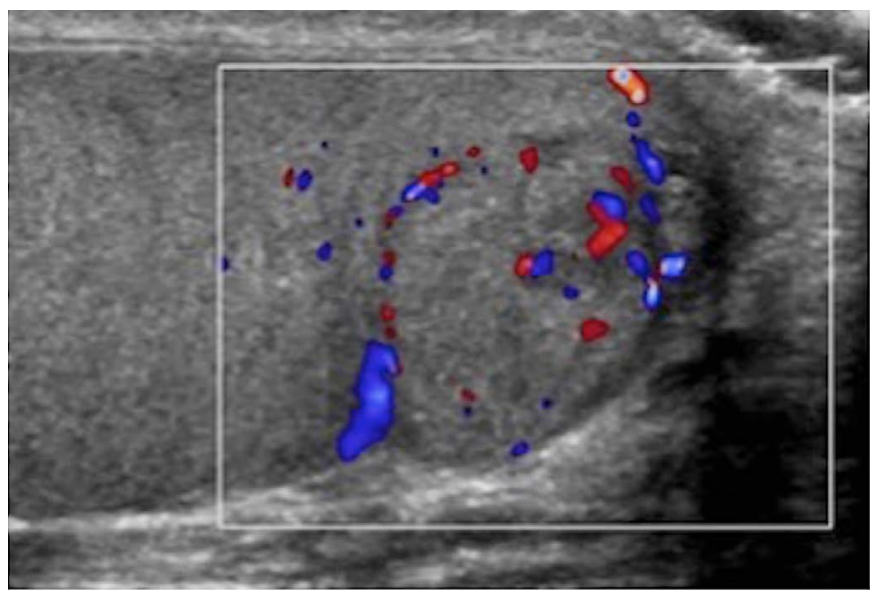

B

Fig. 21. A 26-year-old male with painless right testicular enlargement.

A. Longitudinal gray-scale ultrasonogram of the right testicle demonstrates a heterogeneous mass that occupies almost the entire testicle (arrows). B. Color Doppler evaluation shows vascularity at the peripheral aspect of the mass. The patient underwent right orchiectomy and the pathology revealed a mixed germ cell tumor with $99 \%$ embryonal carcinoma and $1 \%$ seminoma component. 
differentiate true inflammatory states from tumors mimicking inflammation (Fig. 23).

\section{Non-Germ Cell Tumor}

Sex cord stromal tumors account for the majority of non-germ

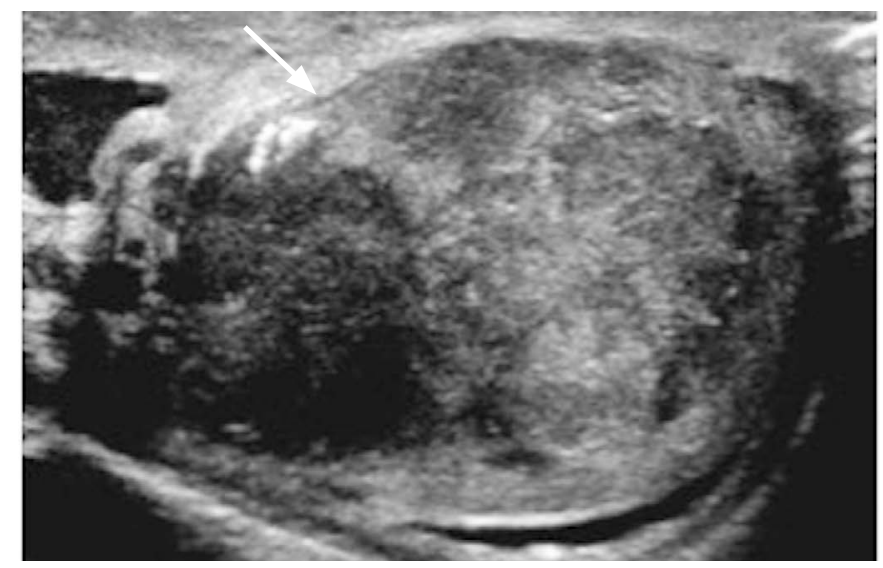

A

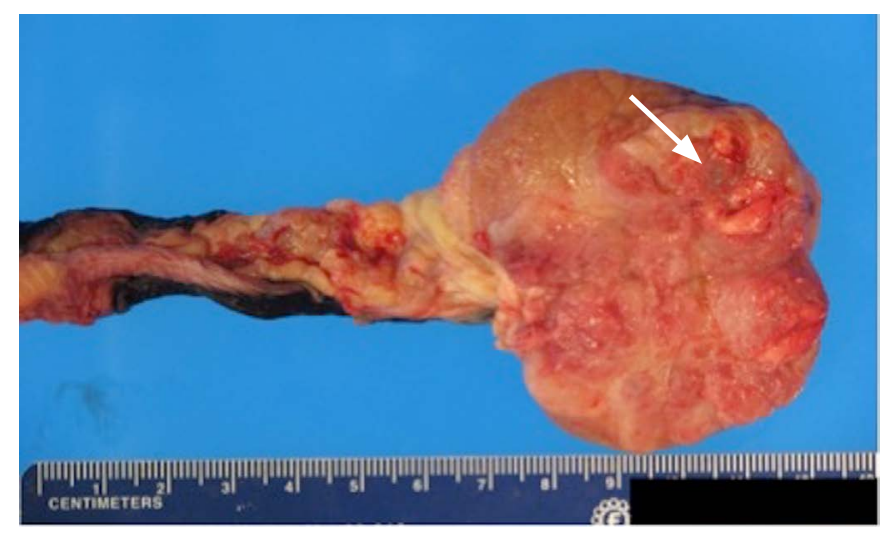

C

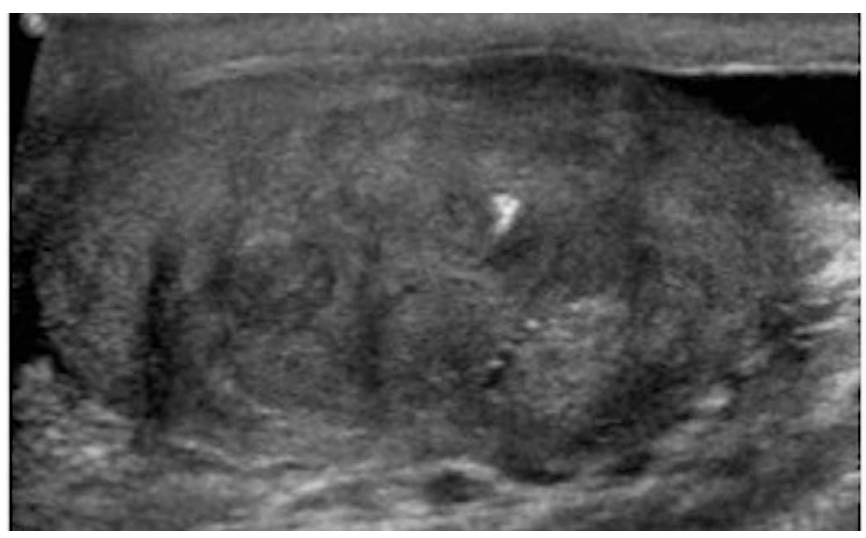

A cell tumors (non-GCTs). These tumors are benign in about $90 \%$ of cases and usually found incidentally due to their small size. Frequently encountered non-GCTs are Sertoli cell tumors and Leydig cell tumors (Fig. 24); far rarer are granulosa cell tumors, fibromathecomas and mixed sex cord stromal tumors. These tumors do not

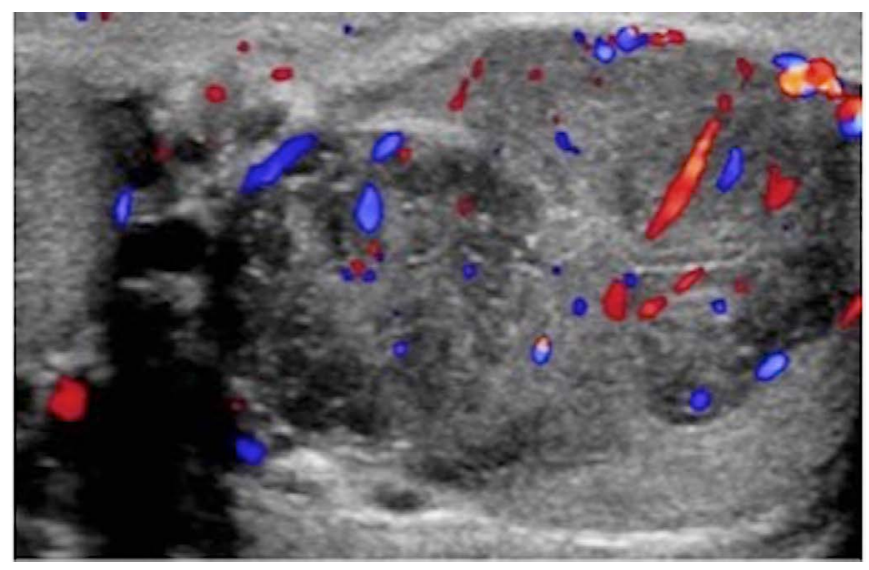

B

Fig. 22. A 33-year-old male with several months of left testicular pain and swelling.

A. Gray-scale ultrasonogram of the left testicle demonstrates an enlarged and heterogeneous testicle (arrow) with nodular, irregular contour. B. Color Doppler evaluation shows diffusely increased vascular flow throughout the testicle. The patient underwent left orchiectomy and the pathology revealed a mixed germ cell tumor with $80 \%$ seminoma and $20 \%$ embryonal carcinoma component. C. Macroscopic pathology specimen of the left testicular mass reveals a well-circumscribed, homogeneous, brown-gray tumor (arrow).

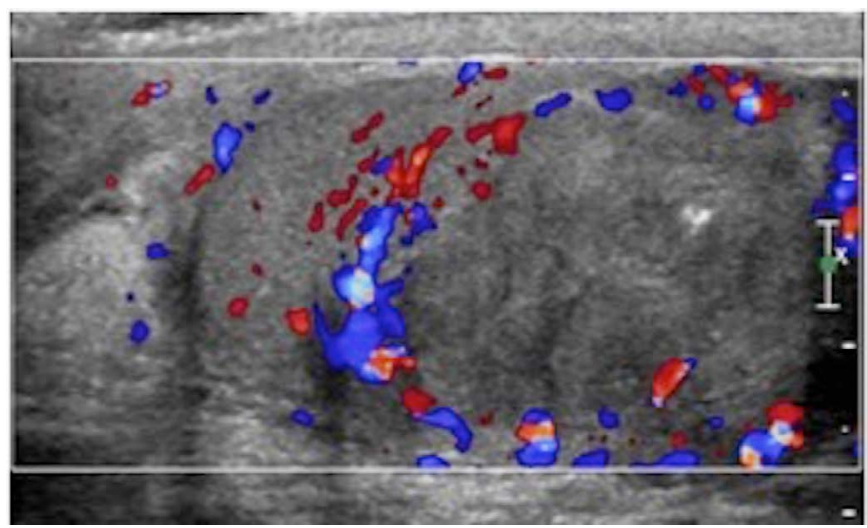

B

Fig. 23. A 31-year-old male with left scrotal pain.

A. Gray-scale ultrasonogram demonstrates mass-like heterogeneous echotexture of the left testicle with associated cystic areas and a focal area of calcification. B. Increased color Doppler flow surrounding the mass in the left testicle is seen. 


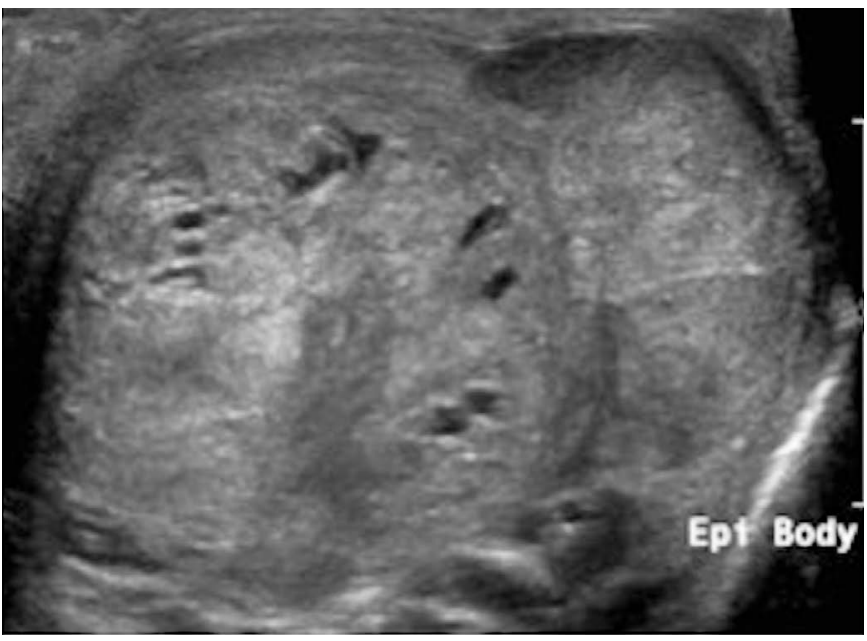

C

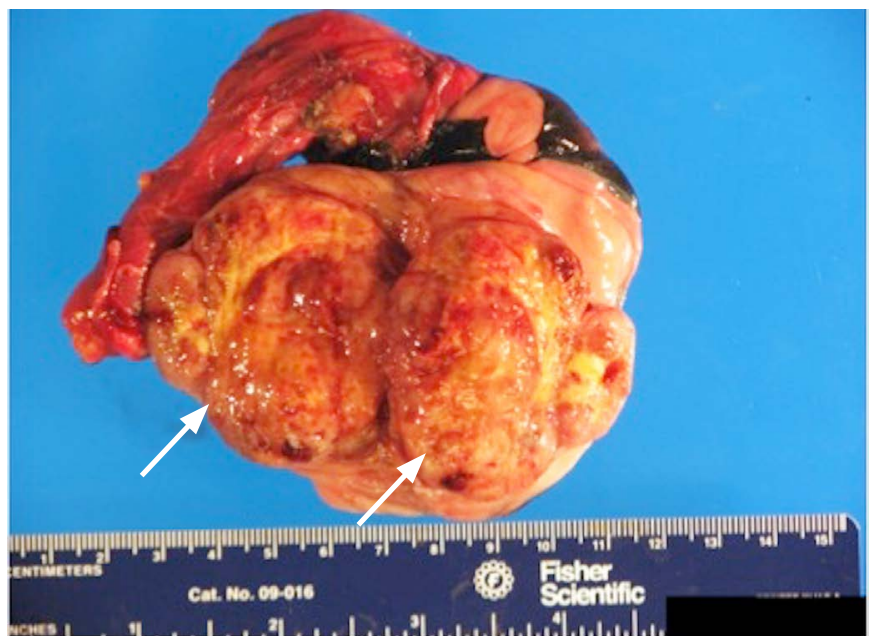

D

Fig. 23. C. Three-month follow-up ultrasonography again demonstrates a large heterogeneously echogenic mass involving the majority of the left testicle. This mass was found to be a mixed germ cell tumor (including embryonal carcinoma 65\%, teratoma 15\%, choriocarcinoma 10\%, yolk sac tumor $5 \%$ and seminoma $<5 \%$ ) on pathology evaluation after left orchiectomy. D. Macroscopic pathology specimen demonstrates the entire left testicle with adjacent spermatic cord and epididymis. A palpable firm mass measuring $5.2 \times 4.7 \times 3.2 \mathrm{~cm}$ was found to protrude into the tunica albuginea. The mass replaces most of the testicle and demonstrates a heterogeneous tan/yellow, hemorrhagic and necrotic cut surface (arrows).

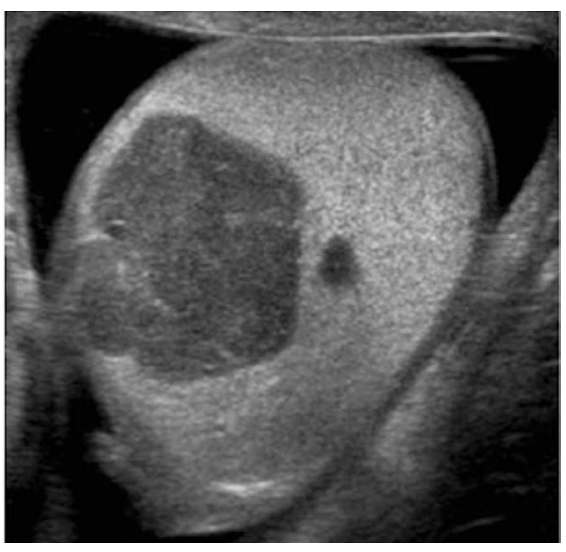

A

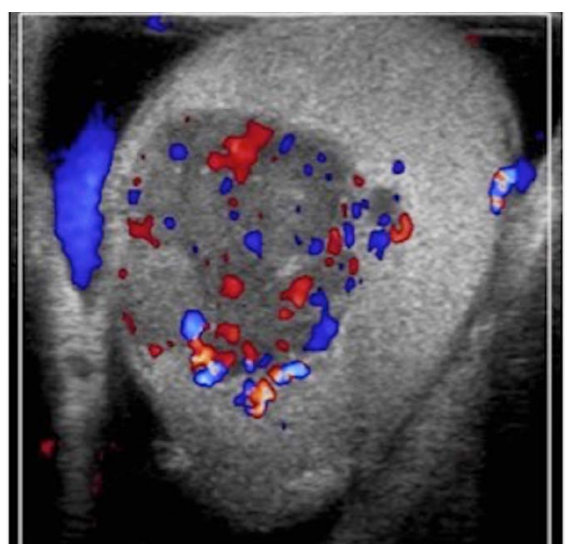

B

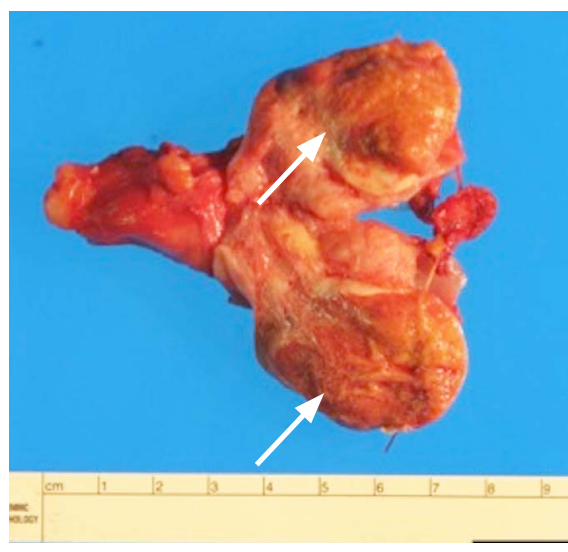

C

Fig. 24. A 59-year-old male with a painless left testicular mass.

A, B. Transverse gray-scale ultrasonogram shows a predominantly hypochoic lobulated mass in the testicle (A), with increased internal vascularity (B). The patient underwent left orchiectomy and the pathology was consistent with a Leydig cell tumor. C. Macroscopic pathology specimen consisted of the left testicle and spermatic cord. The testicle is bivalved to reveal mass (arrows) measuring $5.0 \times 3.0 \times 2.0 \mathrm{~cm}$ with a heterogeneous solid cut surface and areas of hemorrhage and necrosis. The residual testicular parenchyma appears tan-pink and unremarkable.

exhibit specific ultrasonographic characteristics but appear as welldefined hypoechoic lesions. Given the nonspecific appearance on ultrasonography, orchiectomy is usually performed.

\section{Summary}

Ultrasonography remains the first-line imaging modality for evaluation of acute or chronic scrotal diseases. It is a safe and reliable tool for demonstration of scrotal anatomy, localization of testicular lesions and assessment of vascularity. As several testicular pathologies have characteristic ultrasonographic appearances, ultrasonography is able to appropriately guide patient management and potentially prevent unnecessary surgical intervention.

ORCID: Anna L. Kühn: http://orcid.org/0000-0001-9512-9461; Eduardo Scortegagna: http://orcid.org/0000-0001-6471-7703; Kristina M. Nowitzki: http://orcid.org/0000- 
0001-8344-1845; Young H. Kim: http://orcid.org/0000-0002-0206-5663

\section{Conflict of Interest}

No potential conflict of interest relevant to this article was reported.

\section{References}

1. Thomas RD, Dewbury KC. Ultrasound appearances of the rete testis. Clin Radiol 1993;47:121-124.

2. Dogra VS, Gottlieb RH, Oka M, Rubens DJ. Sonography of the scrotum. Radiology 2003;227:18-36.

3. Horstman WG, Middleton WD, Melson GL, Siegel BA. Color Doppler US of the scrotum. Radiographics 1991;11:941-957.

4. Burks DD, Markey BJ, Burkhard TK, Balsara ZN, Haluszka MM, Canning DA. Suspected testicular torsion and ischemia: evaluation with color Doppler sonography. Radiology 1990;175:815-821.

5. Middleton WD, Siegel BA, Melson GL, Yates CK, Andriole GL. Acute scrotal disorders: prospective comparison of color Doppler US and testicular scintigraphy. Radiology 1990;177:177-181.

6. Luker GD, Siegel MJ. Color Doppler sonography of the scrotum in children. AJR Am J Roentgenol 1994;163:649-655.

7. Caesar RE, Kaplan GW. Incidence of the bell-clapper deformity in an autopsy series. Urology 1994;44:114-116.

8. Middleton WD, Middleton MA, Dierks M, Keetch D, Dierks S. Sonographic prediction of viability in testicular torsion: preliminary observations. J Ultrasound Med 1997;16:23-27.

9. Eaton $S H$, Cendron MA, Estrada CR, Bauer SB, Borer JG, Cilento $\mathrm{BG}$, et al. Intermittent testicular torsion: diagnostic features and management outcomes. J Urol 2005;174(4 Pt 2):1532-1535.

10. Chan PT, Schlegel PN. Inflammatory conditions of the male excurrent ductal system. Part II. J Androl 2002;23:461-469.

11. Buckley JC, McAninch JW. Use of ultrasonography for the diagnosis of testicular injuries in blunt scrotal trauma. J Urol 2006;175:175178.

12. Cohen HL, Shapiro ML, Haller JO, Glassberg K. Sonography of intrascrotal hematomas simulating testicular rupture in adolescents. Pediatr Radiol 1992;22:296-297.

13. Cass AS, Luxenberg M. Testicular injuries. Urology 1991;37:528530.

14. Bhandary $\mathrm{P}, \mathrm{Abbitt} \mathrm{PL}, \mathrm{Watson} \mathrm{L}$. Ultrasound diagnosis of traumatic testicular rupture. J Clin Ultrasound 1992;20:346-348.

15. Jeffrey RB, Laing FC, Hricak H, McAninch JW. Sonography of testicular trauma. AJR Am J Roentgenol 1983;141:993-995.

16. Gooding GA, Leonhardt W, Stein R. Testicular cysts: US findings. Radiology 1987;163:537-538.

17. Dogra VS, Gottlieb RH, Rubens DJ, Oka M, Di Sant Agnese AP. Testicular epidermoid cysts: sonographic features with histopathologic correlation. J Clin Ultrasound 2001;29:192-196.

18. Langer JE, Ramchandani P, Siegelman ES, Banner MP. Epidermoid cysts of the testicle: sonographic and MR imaging features. AJR Am J Roentgenol 1999;173:1295-1299.

19. Woodward PJ, Schwab CM, Sesterhenn IA. From the archives of the AFIP: extratesticular scrotal masses: radiologic-pathologic correlation. Radiographics 2003;23:215-240.

20. Fu YT, Wang HH, Yang TH, Chang SY, Ma CP. Epidermoid cysts of the testis: diagnosis by ultrasonography and magnetic resonance imaging resulting in organ-preserving surgery. $\mathrm{Br} J$ Urol 1996;78:116-118.

21. Moghe PK, Brady AP. Ultrasound of testicular epidermoid cysts. Br J Radiol 1999;72:942-945.

22. Eisenmenger M, Lang S, Donner G, Kratzik C, Marberger M. Epidermoid cysts of the testis: organ-preserving surgery following diagnosis by ultrasonography. Br J Urol 1993;72:955-957.

23. Hricak H, Filly RA. Sonography of the scrotum. Invest Radiol 1983;18:112-121.

24. Rifkin $M D$, Kurtz $A B$, Goldberg BB. Epididymis examined by ultrasound. Correlation with pathology. Radiology 1984;151:187190.

25. Jarvis $L$, Dubbins PA. Changes in the epididymis after vasectomy: sonographic findings. AJR Am J Roentgenol 1989;152:531-534.

26. Holden $A$, List A. Extratesticular lesions: a radiological and pathological correlation. Australas Radiol 1994;38:99-105.

27. Reddy NM, Gerscovich EO, Jain KA, Le-Petross HT, Brock JM. Vasectomy-related changes on sonographic examination of the scrotum. J Clin Ultrasound 2004;32:394-398.

28. Frates MC, Benson CB, Stober SL. Mobile echogenicities on scrotal sonography: is the finding associated with vasectomy? I Ultrasound Med 2011;30:1387-1390.

29. Meacham RB, Townsend RR, Rademacher D, Drose JA. The incidence of varicoceles in the general population when evaluated by physical examination, gray scale sonography and color Doppler sonography. J Urol 1994;151:1535-1538.

30. Black JA, Patel A. Sonography of the abnormal extratesticular space. AJR Am J Roentgenol 1996;167:507-511.

31. Rudloff U, Holmes RJ, Prem JT, Faust GR, Moldwin R, Siegel D. Mesoaortic compression of the left renal vein (nutcracker syndrome): case reports and review of the literature. Ann Vasc Surg 2006;20:120-129.

32. Micallef $M$, Torreggiani WC, Hurley $M$, Dinsmore WW, Hogan B. The ultrasound investigation of scrotal swelling. Int J STD AIDS 2000;11:297-302.

33. Collings C, Cronan JJ, Grusmark J. Diffuse echoes within a simple hydrocele: an imaging caveat. J Ultrasound Med 1994;13:439-442.

34. Gooding GA, Leonhardt WC, Marshall G, Seltzer MA, Presti IC Jr. Cholesterol crystals in hydroceles: sonographic detection and possible significance. AJR Am J Roentgenol 1997;169:527-529.

35. Peterson AC, Bauman JM, Light DE, McMann LP, Costabile RA. The prevalence of testicular microlithiasis in an asymptomatic 
population of men 18 to 35 years old. J Urol 2001;166:2061-2064.

36. Smith WS, Brammer HM, Henry M, Frazier H. Testicular microlithiasis: sonographic features with pathologic correlation. AJR Am J Roentgenol 1991;157:1003-1004.

37. Janzen DL, Mathieson JR, Marsh Jl, Cooperberg PL, del Rio P, Golding RH, et al. Testicular microlithiasis: sonographic and clinical features. AJR Am J Roentgenol 1992;158:1057-1060.

38. Yee WS, Kim YS, Kim SJ, Choi JB, Kim SI, Ahn HS. Testicular microlithiasis: prevalence and clinical significance in a population referred for scrotal ultrasonography. Korean J Urol 2011;52:172177.

39. Ganem JP, Workman KR, Shaban SF. Testicular microlithiasis is associated with testicular pathology. Urology 1999;53:209-213.

40. DeCastro BJ, Peterson AC, Costabile RA. A 5-year followup study of asymptomatic men with testicular microlithiasis. J Urol 2008; 179:1420-1423.

41. Costabile RA. How worrisome is testicular microlithiasis? Curr Opin Urol 2007;17:419-423.

42. Kosan M, Gonulalan U, Ugurlu O, Oztekin V, Akdemir O, Adsan 0 .Testicular microlithiasis in patients with scrotal symptoms and its relationship to testicular tumors. Urology 2007;70:1184-1186.

43. Dewbury KC. Scrotal ultrasonography: an update. BJU Int 2000;86 Suppl 1:143-152.

44. Leonhardt WC, Gooding GA. Sonography of intrascrotal adenomatoid tumor. Urology 1992;39:90-92.

45. Srigley JR, Hartwick RW. Tumors and cysts of the paratesticular region. Pathol Annu 1990;25 Pt 2:51-108.

46. Woodward PJ, Sohaey R, O'Donoghue MJ, Green DE. From the archives of the AFIP: tumors and tumorlike lesions of the testis: radiologic-pathologic correlation. Radiographics 2002;22:189-216.

47. Dogra VS, Gottlieb RH, Rubens DJ, Liao L. Benign intratesticular cystic lesions: US features. Radiographics 2001;21 Spec No:S273281.

48. Guthrie JA, Fowler RC. Ultrasound diagnosis of testicular tumours presenting as epididymal disease. Clin Radiol 1992;46:397-400.

49. Geraghty MJ, Lee FT Jr, Bernsten SA, Gilchrist K, Pozniak MA, Yandow DJ. Sonography of testicular tumors and tumor-like conditions: a radiologic-pathologic correlation. Crit Rev Diagn Imaging 1998;39:1-63. 